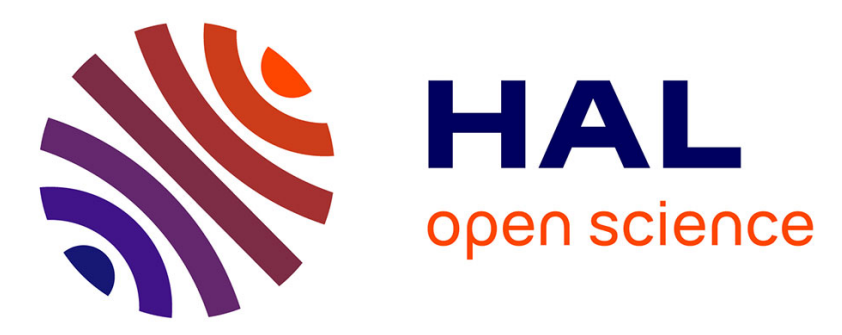

\title{
Extreme Ultraviolet Multilayer Nanostructures and Their Application to Solar Plasma Observations: A Review
}

Alain J Corso, Maria R. Pelizzo

\section{- To cite this version:}

Alain J Corso, Maria R. Pelizzo. Extreme Ultraviolet Multilayer Nanostructures and Their Application to Solar Plasma Observations: A Review. Journal of Nanoscience and Nanotechnology, 2019, 19 (1), pp.532 - 545. 10.1166/jnn.2019.16477 . hal-01909384

\section{HAL Id: hal-01909384 \\ https://hal.science/hal-01909384}

Submitted on 21 Nov 2018

HAL is a multi-disciplinary open access archive for the deposit and dissemination of scientific research documents, whether they are published or not. The documents may come from teaching and research institutions in France or abroad, or from public or private research centers.
L'archive ouverte pluridisciplinaire HAL, est destinée au dépôt et à la diffusion de documents scientifiques de niveau recherche, publiés ou non, émanant des établissements d'enseignement et de recherche français ou étrangers, des laboratoires publics ou privés. 


\title{
Extreme Ultraviolet Multilayer Nanostructures and Their Application to Solar Plasma Observations: A Review
}

\author{
Alain J. Corso ${ }^{1, *}$ and Maria G. Pelizzo $0^{1,2}$ \\ ${ }^{1}$ National Research Council of Italy-Institute for Photonics and Nanotechnologies - Padova, via Trasea 7, 35131 Padova, Italy \\ ${ }^{2}$ Department of Information Engineering, University of Padova, via Gradenigo 6B, 35131 Padova, Italy
}

\begin{abstract}
The advent of nanoscale multilayer (ML) technology has led to great breakthroughs in many scientific and technological fields such as nano-manufacturing, bio-imaging, atto-physics, matter physics and solar physics. ML nanostructures are an enabling technology for the development of mirrors and reflective gratings having high efficiency at normal incidence in the extreme ultraviolet (EUV) range, a spectral region where conventional coatings show a negligible reflectance. In solar physics, ML mirrors have proved to be key elements for both imaging and spectroscopy space instruments, as they allow to make observations of EUV solar plasma emissions with spatial and spectral resolutions never reached before. ML-based instruments have been used in many of the major solar satellites and have flown in numerous sounding rocket experiments; moreover, in the last two decades many studies were performed in order to develop ML structures with increasingly better performance for future solar missions. In this paper, a review of the most promising ML nanostructures developed so far and applied to the observation of solar plasma emission lines is presented. After a brief recall of ML theory, a detailed discussion of the most promising material pairs and layer stack structures proposed and applied to past and current space missions will be presented; in particular, the review will focus on the ML structures having high efficiency in the $6 \mathrm{~nm}-35 \mathrm{~nm}$ wavelength range. Finally, the ML stability to low energy ion bombardment will be discussed.
\end{abstract}

Keywords: Extreme Ultravaiolet, Soft-X Rays, EUV, Multilayer, Solar Physics, EUV Space Instrumentation, Si/Mo, Mg/SiC, Al/Zr, Mo/Y, Pd/B4C.

\section{CONTENTS}

1. Introduction . . . . . . . . . . . . . . . . . . . 532

2. EUV Multilayer Theory ................... 534

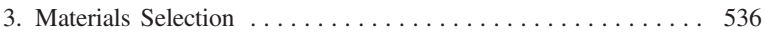

3.1. Silicon-Based EUV ML Structures ... . . . . . . . . . 536

3.2. Al-Based EUV ML Structures . . . . . . . . . . . . 538

3.3. Mg-Based EUV ML Structures . . . . . . . . . . . . . . 539

3.4. ML Structures for Wavelength Shorter than $\mathrm{Si}_{2,3}$

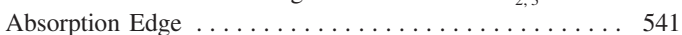

4. Stability to Accelerated Ions Implantation . . . . . . . . . . . . 542

5. Conclusions . . . . . . . . . . . . . . . . . . . . . . . . 542

References and Notes ... . . . . . . . . . . . . . . . 542

\section{INTRODUCTION}

Since the beginning of space exploration, many satellites were devoted to the study of the inner heliosphere and the solar dynamics with the scope to discover the processes that regulate the physics of the Sun. Remote sensing observations of the solar disk and corona combined with

*Author to whom correspondence should be addressed. in situ measurements of solar wind plasma and interplanetary magnetic field are pivotal to understand the dynamics of space weather and its influence on Earth. ${ }^{1}$ In particular, high spatial resolution and high signal-to-noise ratio observations in the Extreme Ultraviolet (EUV) spectral region are required to study many dynamic processes of the solar atmosphere such as jets, coronal mass ejections and flares. ${ }^{2}$

One of main issues to be addressed in the development of EUV space instrumentation is the fabrication of reflective components with high efficiency at normal incidence and long term stability. At wavelengths below $40 \mathrm{~nm}$, where many of the interesting solar plasma emission lines are located, all materials show a strong absorption and a low optical contrast; for this reason, at normal incidence, the coatings based on a single layer thin film have a negligible reflectance. ${ }^{3}$ An alternative is to use components working in grazing incidence (GI) configuration, a solution which was largely adopted before the 1980s. Although single layer coatings working in GI are able to achieve notable reflectance in the EUV, imaging systems suffer 
from high aberrations and low collective area. Nanoscale multilayer (ML) technology, made known by the work of Spiller, ${ }^{4}$ represents a great technological breakthrough, allowing the realization of EUV mirrors and reflection gratings with high efficiency at normal incidence. The working principle of the EUV multilayer coatings exploits optical interference. ${ }^{5} \mathrm{~A}$ basic multilayer coating is a stack of nm-scale bi-layers, each of which is composed by two thin layers of optically dissimilar materials; the heavier element (typically with high Z) is called absorber, whereas the lighter one (typically with low Z) is called spacer. The layer thicknesses are designed in order to coherently add all the small reflections occurring at each interface of the stack, making a constructive interference at a specific wavelength.

Nano-manufacturing, bio-imaging, atto-physics, matter physics, solar physics and many other research fields have strongly benefited from the technological possibilities offered by the use of EUV multilayers. In particular, solar observations with higher spatial and spectral resolution than ever before have been obtained. Historically, the first use of an EUV ML coating in a space experiment was in 1985, when a sounding rocket was flown to collect images of the Sun at $44 \AA$ (Si-XII emission) $:^{6}$ the primary mirror of the normal incidence X-ray Herschelian's telescope was coated with a W/C multilayer comprising 30 bi-layers. Two years later, in 1987, Mo/Si MLs were used to coat the mirrors of a Cassegrain's telescope flown on a second sounding rocket experiment; during this flight, high resolution images of the solar disk at $173 \AA$ (Fe IX and $\mathrm{Fe} \mathrm{X}$ lines) and $256 \AA$ (He II line) were successfully recorded for the first time. ${ }^{7,8}$ In the years following, many different sounding rockets carrying instruments with multilayer coatings have been lunched. ${ }^{9-23}$ In 1995 the NASA long term mission Solar and Heliospheric Observatory (SOHO), carrying out a suite of instruments for remote and in-situ observations, has been launched: among the instruments, the EIT imager was a telescope having the primary mirror divided into four sectors, each coated with a different multilayer, allowing the quasi-contemporary observation of different EUV emission lines. ${ }^{24}$ Afterward, multilayer coatings have been regularly employed in all the EUV long-term solar space missions, including TRACE, ${ }^{25}$ STEREO/EUVI, ${ }^{26}$ Hinode/EIS, ${ }^{27}$ SDO/AIA, ${ }^{28}$ PROBA2/SWAP ${ }^{29}$ CORONAS-F/SPIRIT, ${ }^{30}$ SUVI /GOES$\mathrm{R}^{31}$ and CORONAS-PHOTON/TESIS. ${ }^{32}$ Furthermore, EUV multilayer technology was successfully used also on instruments which do not have the Sun as scientific target, including SELENA/TEX. ${ }^{33}$

Currently, a new generation of solar missions is planned. For instance, the European Space Agency (ESA) is preparing Solar Orbiter ${ }^{1}$ whose payload includes the Extreme Ultraviolet Imager (EUI), a suite of off-axis Gregorian and Herschelian telescopes working at $174 \AA$, $304 \AA$ and $1216 \AA$ wavelengths; ${ }^{34}$ similarly, the Japan Aerospace Exploration Agency (JAXA) is developing the Solar-C mission, on board of which a normal-incidence EUV telescope working at $94 \AA, 171 \AA$ and $304 \AA$ wavelengths ${ }^{35}$ is foreseen. In general, the scientific goals expected by the future missions are leading the development of instrumentation with increasingly advanced features, resulting in the need of improving ML performance in terms of reflectance, spectral selectivity, stability to heat, radiation and energetic particles. Narrowband MLs with high
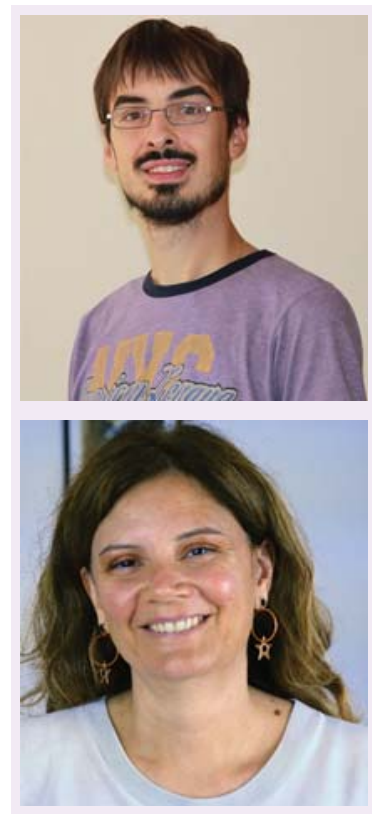

Alain J. Corso has been graduated in Electronic Engineering cum laude at the University of Padova (Italy) in 2010 and he received the PhD in Space Science and Technology from University of Padova in 2014. He is currently researcher at the National Research Council of Italy - Institute for Photonics and Nanotechnology and adjunct professor of optics at the University of Padova. His research interests are mainly focused on optical thin films and development of optical instrumentation for space applications. In particular, he has valuable experience in the development of optical components and instrumentation working in the Extreme Ultraviolet range. He is Co-investigator of the spectrometer PHEBUS on ESA BepiColombo mission and he is involved in METIS coronagraph for ESA Solar Orbiter.

Maria G. Pelizzo received her Ph.D. in Space Science and Technology from the University of Padova, Italy, in 2000. She is currently a researcher of the National Research Council of Italy - Institute for Photonics and Nanotechnologies and adjunct professor of Optics and Photonics at University of Padova. Her research is focused on optical thin films and she has been scientific responsible on various programs in the field of extreme ultraviolet optics for space and free electron laser applications. She is currently the principal investigator of an ESA project devoted to the study of materials and coatings operating in harsh space environment. She is Co-investigator of Metis coronagraph on board of ESA Solar Orbiter, of Phebus spectrometer on board of ESA Bepi-Colombo, and of the Janus camera on board of ESA Juice. 
reflectance peak are pivotal to perform observations with high spectral selectivity, avoiding wavelength inter-mixing and reducing the integration times; likewise, efficient broad-band MLs, which are particularly challenging at wavelengths shorter than that of the $\mathrm{Si}_{2,3}$-edge, ${ }^{36}$ are highly required in spectroscopic instruments. Furthermore, coatings able to withstand harsh environments, including high thermal irradiation, protons, electrons, heavier ions and gamma irradiations are in demand.

In the present paper we review the ML coating nanostructures developed so far and applied to observations of solar plasma emission lines. In order to introduce useful definitions, a brief recall of ML working principles is presented in the second section. The following part will be devoted to a detailed review of all the different material pairs and layer structures researched and applied to past and current space missions in the $6 \mathrm{~nm}-35 \mathrm{~nm}$ spectral range.

\section{EUV MULTILAYER THEORY}

A basic ML is a periodic stack made of a periodic combination of nm-scale bi-layers (Fig. 1(a)). The material with lower density is the spacer (M1) while the one with higher density is the absorber (M2). The reflectance peak at a target wavelength, usually called "the central wavelength," is achieved by optimizing the layer thicknesses in order to add all reflected components at each interface in phase. Although the precise calculation of ML optical performance requires the recursive application of the Fresnel coefficients at each interface, ${ }^{5}$ it is possible to use an approximate relationship. ${ }^{37}$ By neglecting the small effects of the refraction occurring within each layer, the phase difference between the radiation reflected by two consecutive bi-layers is given by

$$
\Delta \phi=\frac{2 \pi}{\lambda_{0}} 2 d \cos \theta
$$

where $d$ is the bi-layer total thickness, $\theta$ is the incidence angle defined from the surface normal direction and $\lambda_{0}$ is the target wavelength. The constructive interference- the condition necessary for the reflectance boosting-occurs when the phase difference is a multiple integer of $2 \pi$. As it is customary for the EUV MLs, the bi-layer thickness is designed in order to work at the first order, i.e., making a phase delay of exactly $2 \pi$, obtaining the condition

$$
\lambda_{0}=2 d \cos \theta
$$

The relationship reported in (2) is "Bragg's law" and it is the most practical approximation to link the bi-layer thickness with the working angle and the central wavelength. This name is derived from the natural crystal X-ray diffraction theory, since the working principle of EUV MLs is similar to that of crystals in the X-ray range. In an actual ML, the thicknesses of the spacer $\left(d_{1}\right)$ and the absorber $\left(d_{2}\right)$ within each bi-layer are chosen in order to maximize the Fresnel coefficients, by taking into account the effects of the interference and the material absorption. The ratio between the spacer thickness $\left(d_{1}\right)$ and the total period of the bilayer $(d)$ is called $\Gamma$.

A ML stack provides high reflectance in a spectral band centered on the target wavelength. An approximate relationship to estimate the bandwidth can be formulated

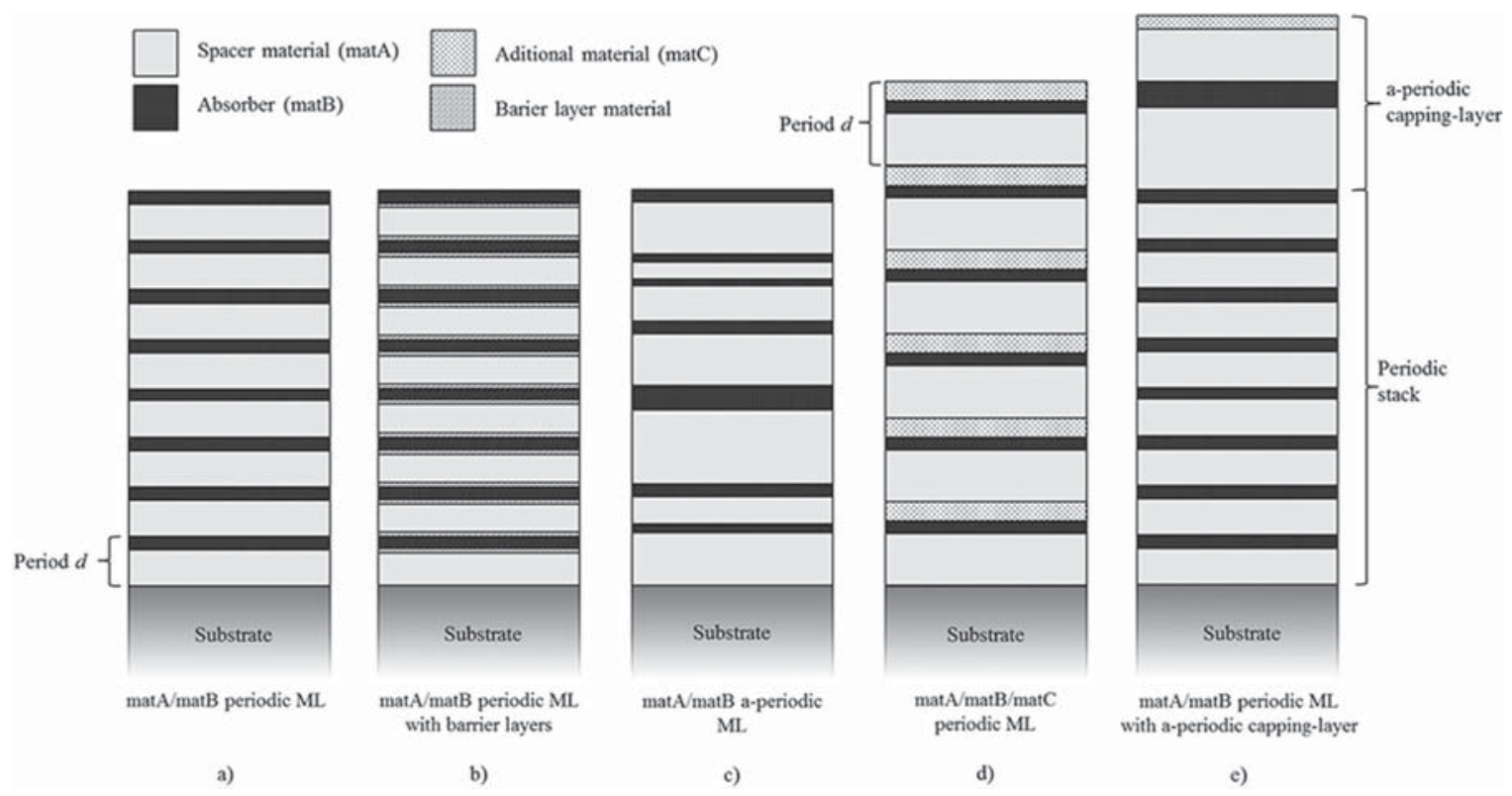

Figure 1. Sketch of different structures adopted in EUV ML reflective coatings realization. 
by considering that the multilayer provides a temporally coherent response. In fact, the waves reflected by the inner bilayers must coherently add with those on the top surface. Physically, this requires the total optical thickness of the multilayer be proportional to the coherence length of the stack, ${ }^{3}$ obtaining:

$$
L=\frac{\lambda_{0}^{2}}{\Delta \lambda} \propto 2 N d \Rightarrow \Delta \lambda \propto \frac{1}{N}
$$

where $N$ is the total number of the bi-layers in the periodic stack and $\Delta \lambda$ is the spectral band defined as the "full width at half maximum" (FWHM). Relationship (3) suggests that a narrow-band response is achievable by increasing the number of bi-layers in the stack. Narrow-band ML coatings are extremely important for all the applications requiring quasi-monochromatic imaging. However, the absorption of the materials composing the ML stack determines a maximum penetration depth, limiting the number of layers that can interacts with the impinging radiation. Thus, for a periodic ML based on a defined material pair, there is a lower limit for the bandwidth that cannot be exceeded by increasing the bi-layer number. In contrast, it is common to broaden the spectral response by reducing the layer number, although this leads also to a drop of the peak reflectance, which scales as $N^{2}$. This approach was used, for example, on the SERTS instrument ${ }^{11}$ and on the Hinode/EIS instrument. ${ }^{38}$ An alternative method for enlarging the spectral band consists of staking blocks of periodic structures with gradually varied periods. Since the reflectance profile of each block is spectrally shifted with respect to the others, the staking process gives a resulting reflectance curve with an enlarged bandwidth. ${ }^{36}$ A more refined approach, which has been largely used in the development of mirrors for photolithography and atto-second pulses manipulation, employs aperiodic structures (Fig. 1(c)). ${ }^{39-42}$ With this method, the integrated reflectances achieved over bandwidth are higher than those obtained by just reducing the number of layers, although such structures are more expensive and require stricter tolerances in layer thickness control. ${ }^{40}$

The overall optical performance of MLs is heavily conditioned by the quality of the layer interfaces. In a real ML, the interfaces between two different materials are not abrupt, but they present imperfections - such as roughness, inter-layer diffuseness and crystallization-which impair the specular reflectance. For instance, the interfacial roughness is responsible for scattering light into non-specular directions, leading to the increase of stray-light and to the correspondent drop of the specular reflected light. Furthermore, diffuseness at interfaces reduces their reflectance, allowing the impinging light to penetrate deeper into the ML stack, with a consequent increase of the total radiation absorption. The roughness, diffuseness and crystallizations occurring at an interface might depend on many factors, such as the deposition conditions, the materials combination or the maximum operational temperature of the ML. In particular, when the materials combination is characterized by interfaces with a naturally poor quality, the total reflection efficiency drops dramatically. A common technique adopted to improve the effects of such interface imperfections consists in the insertion of thin inter-layers which act as barrier layers (Fig. 1(b)). In fact, the timely choice of the thickness and the barrier-layer material-which guarantees low absorption at the working wavelengths and the formation of smooth interfaces that are stable over time-allows to contain the inter-diffusion, improving the ML optical performance ${ }^{43-45}$ as well as their thermal and aging stability. ${ }^{46,47}$

An additional solution to improve the native performance of a ML structure is to employ a tri-component periodic stack (Fig. 1(d)). ${ }^{48,49}$ In a standard two-materials stack, the optical contrast can be achieved by using materials with low and high absorption; ${ }^{48}$ however, the high-absorbing component limits the maximum reflectance achievable by the structure. In a tri-component system, the material with high absorption is replaced by two moderately absorbing materials, reducing the total absorption of the ML and then improving the maximum achievable reflectance. ${ }^{48}$

ML performance is highly affected by surface oxidation and/or contamination occurring during the operational life of any space instrument. Surface oxidation as well as contamination can occur at any time during ground operations, at the development and integration of the instrument. Furthermore, solar instruments-telescopes, spectrographs and radiometers-are particularly vulnerable in space because their optical elements are unshielded and thus directly exposed to the environmental agents. ${ }^{50}$ For example, solar instruments flying onboard of low Earth orbit satellites are heavily subjected to both $\mathrm{O}$ atoms and other ions species bombardment, which induces surface oxidation/contamination of the EUV optics. Moreover, instruments suffer substantial degradation due to synergistic effects of solar irradiation and contamination released by the spacecraft itself: in fact, the outgassed organic compounds can be polymerized by the solar radiation, causing an irreversible deposition of these same compounds on the instrument optical surfaces. ${ }^{51}$ Organic contamination and oxidation of the mirror surfaces is a well-known problem also in the synchrotron, FEL and EUV lithography user communities, who have developed different approaches in order to mitigate such effects, such as cleaning procedures ${ }^{51,52}$ and use of oxidation-resistant capping layers. ${ }^{53}$ While the cleaning procedures are unserviceable in space, the use of protective capping layers offers great benefits when adopted in solar physics instrumentation. A protective capping layer is usually a thin layer of few nanometers placed on top of a ML stack; an oxidation-resistant and chemically stable material is a good candidate as capping layer ${ }^{54}$ Moreover, the "capping layer technology" can be exploited to increase the 
reflectance peak at a specific wavelength, to slightly modify the spectral performance of a periodic stack or even to improve the stability over time. For example, Ir and $\mathrm{Ru}$ capping-layers were used to improve the native EUV performance of periodic Mo/Si stacks. ${ }^{55}$ Similarly, aperiodic capping layers (Fig. 1(e)) were exploited to implement an anti-reflection coating able to reject one wavelength while boosting its third harmonics, ${ }^{56-58}$ aperiodic capping layers were also proposed to improve the spectral purity of a periodic ML tuned at the $28.4 \mathrm{~nm}$ spectral line.${ }^{59}$ Recently, some studies have demonstrated that capping layers can play an important role as protective layers, improving the coating stability over time ${ }^{60}$ and the stability against ions irradiation. ${ }^{61,62}$

\section{MATERIALS SELECTION}

The performance of a ML coating in the $6 \mathrm{~nm}-35 \mathrm{~nm}$ wavelength range is strongly dependent on the selection of the layer materials. Standard periodic ML coatings require the selection of at least one spacer material having minimum absorption in the target spectral range. The ideal candidate as a spacer is a material having an absorption edge just below the desired wavelength range. Different materials having this feature are available in the $6-35 \mathrm{~nm}$ wavelength range, including $\mathrm{Mg}, \mathrm{Al}, \mathrm{Si}, \mathrm{Be}, \mathrm{Y}, \mathrm{B}$ (Fig. 2). The second material is selected among those having a large optical contrast with respect to the spacer one. By thinking in terms of optical constants, this is equivalent to selecting materials having values of the real part $n$ and imaginary part $k$ of the refractive index as different as possible while maintaining a reasonable low value for $k$.

In addition to the optical proprieties of the materials, it is important to also take into account their physical and chemical properties. The best material pairs should form smooth and compositionally abrupt interfaces when deposited. In order to ensure a good stability over time, they should have low inter-diffusivity and low chemical reactivity (low miscibility) with common gas species such as oxygen, nitrogen, water vapor, sulfur. Finally, the health hazard is an aspect that should be carefully considered.

Based on the data available in the literature, a selection of the most highly performing ML structures for solar physics plasma observations has been carried out (Fig. 2). Each of the listed proposed structures is discussed in the following sections.

\subsection{Silicon-Based EUV ML Structures}

The $\mathrm{L}_{2,3}$-absorption edge of Silicon at about $\lambda \sim 12.4 \mathrm{~nm}$ of silicon makes this material suitable for a big variety of EUV ML structures. The Mo/Si multilayer stack is among the most-studied MLs since the mid 80's ${ }^{63}$ and perhaps the best-known. The near normal-incidence reflectance attainable with $\mathrm{Mo} / \mathrm{Si}$ approaches $70 \%$ for wavelengths just above the Si L-edge (where EUV lithographic apparatus operate) ${ }^{64,65}$ although the reflectance peak drops steadily at longer wavelengths. $\mathrm{Mo} / \mathrm{Si} \mathrm{ML}$ is also a reference coating for solar applications since it was successfully employed in many long-term missions like SOHO/EIT, ${ }^{24}$ Hinode/EIS, ${ }^{27}$ SDO/AIA,${ }^{28}$ CORONAS-F/SPIRIT,${ }^{30}$ SUVI /GOES-R ${ }^{31}$ or CORONAS-PHOTON/TESIS, ${ }^{32}$ showing an appreciable stability over time. At $30.4 \mathrm{~nm}$ (He II Lyman$\alpha$ line) $\mathrm{Mo} / \mathrm{Si}$ reaches a reflectance peak of $20 \%$ with a FWHM band of about $2-3 \mathrm{~nm} ;{ }^{55-67}$ at $28.4 \mathrm{~nm}$ (Fe XV line) it can give a reflectance peak of about $22 \%$, with a FWHM band of $1.6 \mathrm{~nm}$; at $19.4 \mathrm{~nm}$ it has a reflectance peak of about $43 \%$ with a FWHM band of $1 \mathrm{~nm} ;{ }^{68,69}$ at $17.1 \mathrm{~nm}$ (Fe IX line) it reaches a reflectance of about $53 \%$ with a band of $0.9 \mathrm{~nm} .{ }^{68}$ Figure 3 reports the simulation of the maximum reflectance peak expected by a $\mathrm{Mo} / \mathrm{Si}$ periodic ML structure when it is optimized for a specific wavelength; in the same figure, the best performances experimentally measured for different $\mathrm{Mo} / \mathrm{Si} \mathrm{ML}$ mirrors are reported as well.

Simulations demonstrate that MLs having Si as topmost layer offer lower reflectance with respect to the case where the $\mathrm{Mo} / \mathrm{Si}$ stack is terminated with a Mo layer. However,

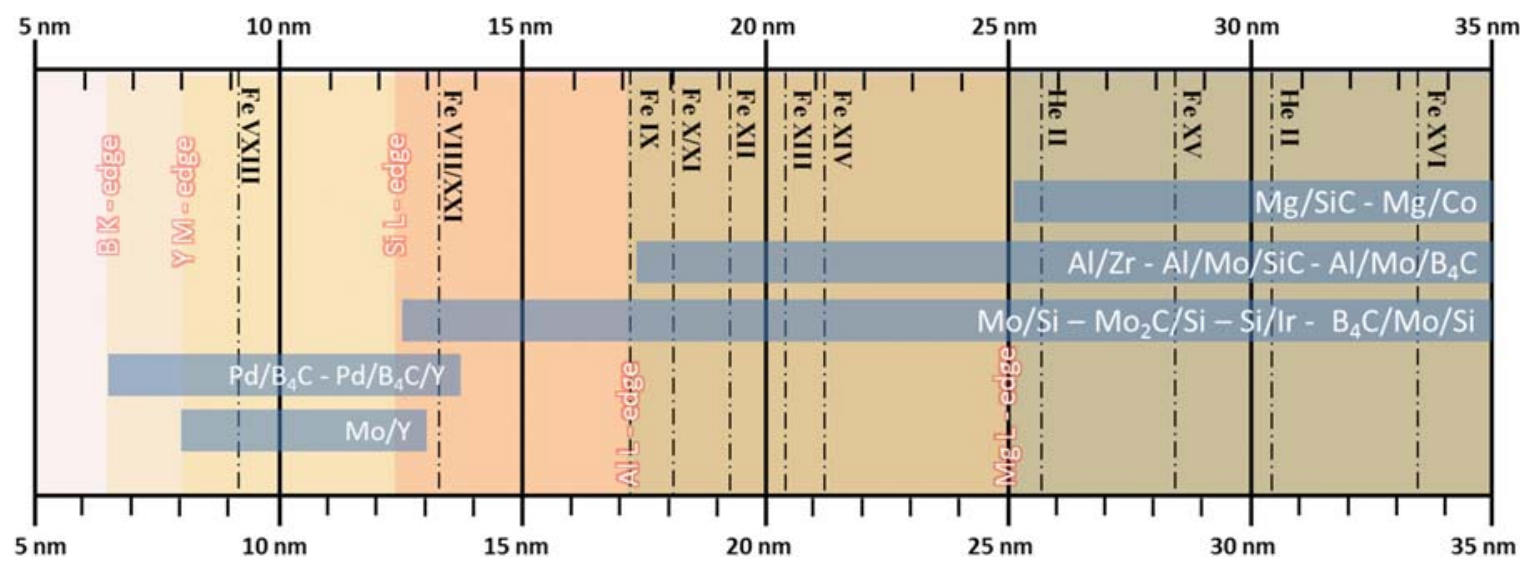

Figure 2. Material selection chart. 

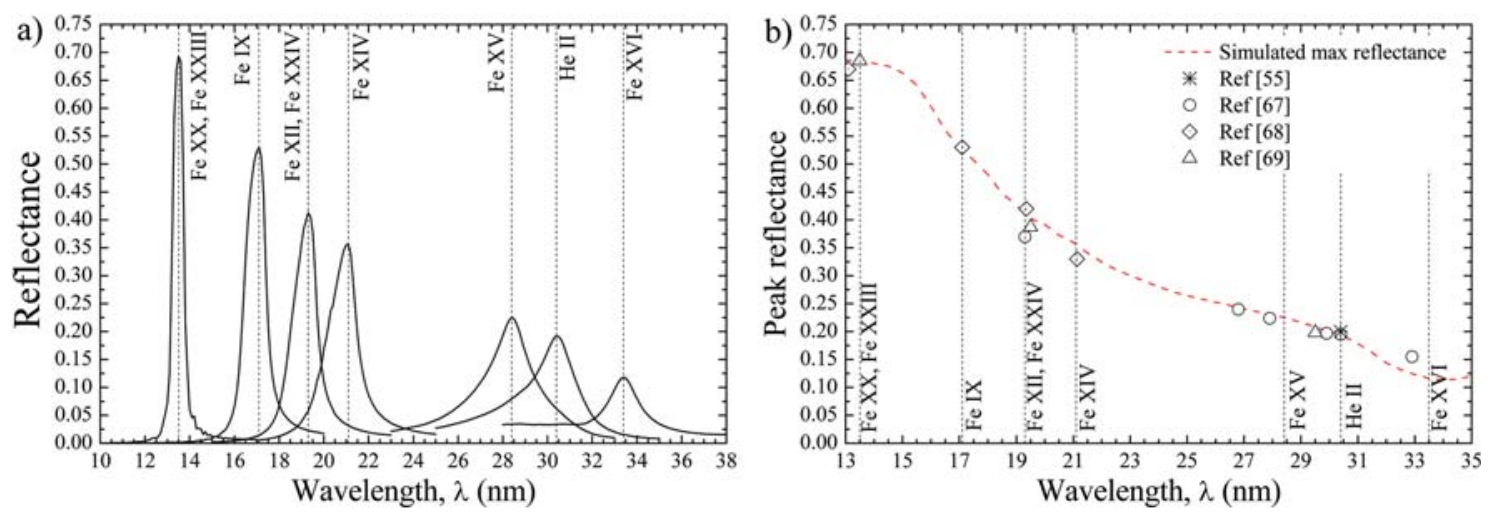

Figure 3. (a) Simulation of the spectral reflectance expected from a Mo/Si stack in a set of wavelengths useful in solar plasma physics; (b) peak reflectance expected at each wavelength by an optimized $\mathrm{Mo} / \mathrm{Si}$. For all simulations, the optical constants adopted for all materials are those currently available at the CXRO website: ${ }^{70}$ for Si the optical constants are those provided in Ref. [71] while for Mo are those provided in Ref. [72] (for wavelengths $>20.4 \mathrm{~nm}$ ) and Ref. [73] (for wavelengths $<20.4 \mathrm{~nm}$ ). The inter-diffusion at interfaces considered in the simulations was modeled with an error function of $\sigma=0.6 \mathrm{~nm}$, which corresponds to an average value among those available in literature. ${ }^{55,66,74}$ In (b) the experimental reflectance peaks reported in Refs. $[55,67,68,69]$ are shown as well.

experimental evidence has demonstrated that the degradation in reflectance induced by the oxidation of the topmost Mo layer is much more dramatic than that caused by $\mathrm{Si}$ partial oxidation. ${ }^{67}$ The native performance of $\mathrm{Mo} / \mathrm{Si}$ stacks in term of peak reflectance and spectral band purity can be improved by using capping-layers. Ir and $\mathrm{Ru}$ thin films were deposited on-top of a $\mathrm{Mo} / \mathrm{Si}$ periodic stack in order to improve the EUV performance at $30.4 \mathrm{~nm}$, successfully increasing the reflectance up to $26 \% .^{55}$

The FWHM spectral band of a Mo/Si ML is a limiting parameter in many applications. For example, the observation of the Fe XV line at $28.4 \mathrm{~nm}$ performed by using periodic $\mathrm{Mo} / \mathrm{Si}$ is seriously affected by the close and bright He II line at $30.4 \mathrm{~nm}$, which still falls in the ML spectral band. For example, in EIT instrument this problem was overcame reaching a HeII line rejection between 100 and 1000 by using an aperiodic structure with a reduced number of layers, although this approach produced a reduction of the reflectance at $28.4 \mathrm{~nm} .{ }^{24,75}$ Alternatively, the use of capping-layers-consisting of a set of $\mathrm{Si}$ and $\mathrm{Mo}$ aperiodic layers deposited on top of a periodic structurewere proposed to improve the spectral purity of a standard periodic $\mathrm{Mo} / \mathrm{Si}$ stack tuned at Fe XV line, ${ }^{59}$ a similar approach was also adopted to improve the spectral purity of a FEL beam. ${ }^{57}$ Such layers are designed in order to reject the $30.4 \mathrm{~nm}$ wavelength without compromising the reflectance at $28.4 \mathrm{~nm}$. In Figure 4(a), a simulation of a $\mathrm{Mo} / \mathrm{Si} \mathrm{ML}$ tuned at $28.4 \mathrm{~nm}$ having an anti-reflection capping-layer at $30.4 \mathrm{~nm}$ is compared with the performance of a standard periodic Mo/Si stack. The design of
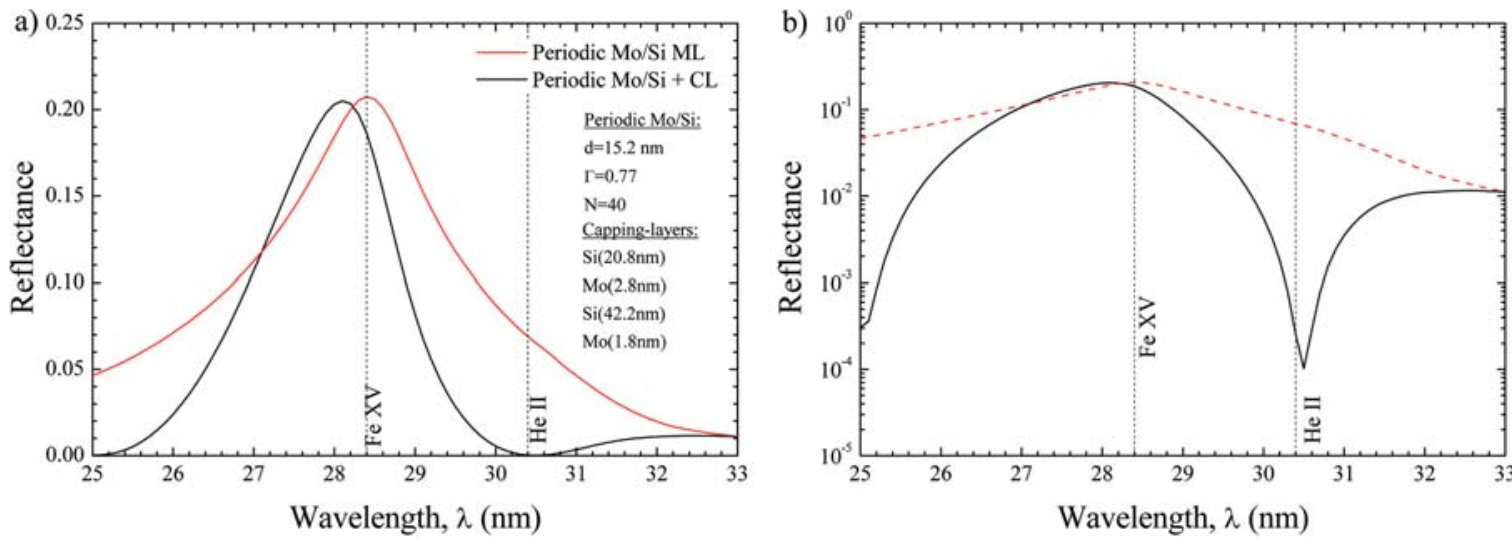

Figure 4. Simulation of a periodic Mo/Si ML tuned at $28.4 \mathrm{~nm}$ with and without the capping layers for the rejection of the $30.4 \mathrm{~nm}$ line; the reflectance curves versus wavelength of both structures are reported in linear scale (a) and in logarithmic scale (b). The design was performed by following the methods proposed in Ref. [59]: the parameters of the two structures are also reported in the figure. The optical constants adopted for Si are those provided in Ref. [71] while for Mo are those provided in Ref. [72] The inter-diffusion at interfaces was modeled with an error function with $\sigma=0.6 \mathrm{~nm}$. 
these two coatings has been performed by following the methods proposed in Ref. [59]; the resulting parameters are reported in Figure 4(b). The capped structure has a slight peak shift which causes a small loss of reflectance at $28.4 \mathrm{~nm}$ (peak reflectance drop from $20 \%$ to $18.5 \%$ ); on the other hand, the reflectance at $30.4 \mathrm{~nm}$ is lower than $0.1 \%$, gaining a high rejection for this line.

In addition to the Mo/Si MLs, many different Si-based structures have been investigated, including $\mathrm{Mo}_{2} \mathrm{C} / \mathrm{Si}$, $\mathrm{Si} / \mathrm{B}_{4} \mathrm{C}, \mathrm{Si} / \mathrm{C}, \mathrm{Si} / \mathrm{SiC}$ and $\mathrm{Ir} / \mathrm{Si}$. For example, the TRACE instrument employed $\mathrm{Mo}_{2} \mathrm{C} / \mathrm{Si}$ multilayers, ${ }^{25}$ a structure having optical performance similar to that of a traditional $\mathrm{Mo} / \mathrm{Si}$ stack but with a better thermal stability ${ }^{76,77}$ and a slightly narrower spectral response. ${ }^{25,67}$ An interesting alternative structure is the $\mathrm{Si} / \mathrm{B}_{4} \mathrm{C} \mathrm{ML}$, which is able to reach a reflectance of $30 \%$ at $30 \mathrm{~nm}$ and a reflectance of about $36 \%$ at $28 \mathrm{~nm} .{ }^{67}$ Its performance appears promising, but at this moment this structure is unsuitable for space applications because of its adhesion problems; in fact, the high stress in the film leads to a coating delamination just about ten months after deposition. ${ }^{67} \mathrm{The} \mathrm{Si} / \mathrm{C}$ and $\mathrm{Si} / \mathrm{SiC}$ MLs show similar or slightly lower performance with respect to those achievable with $\mathrm{Mo} / \mathrm{Si}$, making disadvantageous the use of these coatings. ${ }^{67}$

Recently, a promising coating exploiting Ir as absorber layer was proposed for solar plasma observations. ${ }^{78}$ The ML mirror presented was composed by a periodic stack of 30 periods with an aperiodic capping layer. It showed a reflectance of $24.4 \%$ at $30.4 \mathrm{~nm}$ with a spectral band slightly narrower with respect to the standard $\mathrm{Mo} / \mathrm{Si}$. Moreover, Ir/Si ML seems to be stable over time as the reflectance peak has been proved to be unchanged after 21 months (Fig. 5).

The theoretical peak reflectance of the $\mathrm{Ir} / \mathrm{Si}$ multilayer expected by assuming perfectly smooth and sharp interfaces is $28 \%$. The diminishing of the peak reflectance

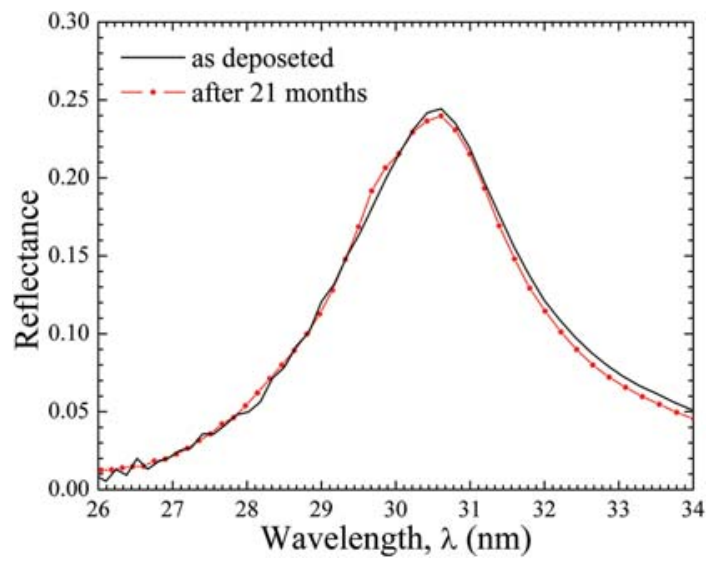

Figure 5. Comparison of the experimental reflectance of a $\mathrm{Ir} / \mathrm{Si} \mathrm{ML}$ structure described in Ref. [78] measured two weeks and 21 months after deposition. The measurements were performed at BEAR beam line at ELETTRA synchrotron, Trieste (Italy). measured (i.e., 24\%) is mainly due to inter-diffusion at the interfaces. In Ref. [78] a model taking into account interface roughness and inter-diffusion effects was built to fit the experimental values; based on such a model, simulation of the maximum reflectance achievable at different wavelengths by an Ir/Si periodic ML stack has been computed and reported in Figure 6. The results show that the $\mathrm{Ir} / \mathrm{Si}$ structure is particularly convenient for wavelengths longer than $28 \mathrm{~nm}$, were the reflectance peak is greater than the $\mathrm{Mo} / \mathrm{Si}$ one. In particular, Ir/Si seems to be a valid choice at $33.5 \mathrm{~nm}$ (Fe XVI line) where it reaches a reflectance of $28 \%$ with a FWHM spectral band of about $3 \mathrm{~nm}$. An additional potential improvement of its optical efficiency might be achieved by using appropriate barrier layers, a method which was already adopted for breaking the "70\% threshold at $13.5 \mathrm{~nm}$ " in Mo/Si coatings. ${ }^{43,79}$ Higher EUV reflectance in the wavelength range $20 \mathrm{~nm}$ to $40 \mathrm{~nm}$ can be achieved by adding a third material $\left(\mathrm{B}_{4} \mathrm{C}\right)$ in the periodic $\mathrm{Mo} / \mathrm{Si}$ structure. ${ }^{49} \mathrm{~B}_{4} \mathrm{C} / \mathrm{Mo} / \mathrm{Si}$ multilayer tuned at $32 \mathrm{~nm}$ shows a stable normal incidence reflectance of $34 \%$ over eight months. ${ }^{49}$ This tri-component system was also designed for imaging the He II plasma emission line and it was adopted in the EUV coronagraph HECOR which flown onboard of Herschel sounding rocket. ${ }^{23}$

\subsection{Al-Based EUV ML Structures}

Reflectance and bandwidth simulations predict very promising performance for multilayers using $\mathrm{Al}$ as spacer material. In fact, the position of the $\mathrm{Al} \mathrm{L}_{2,3}$-absorption edge makes this material particularly suitable as spacer for wavelengths longer than $17.1 \mathrm{~nm}$, providing better theoretical performance (in terms of reflectance and spectral purity) with respect to the Si-based MLs. However, in Albased systems the inhomogeneous crystallization and the high diffusivity/reactivity of $\mathrm{Al}$ results in the formation of rough interfaces between $\mathrm{Al}$ and the adjacent materials, limiting the actual performance. ${ }^{81-83}$ Furthermore, because $\mathrm{Al}$ is very reactive, the thermal and temporal stability of the combinations is an additional crucial aspect in the practical application of Al-based systems.

Many different material pairs can be considered in principle, such as $\mathrm{Nb} / \mathrm{Al}, \mathrm{SiO}_{2} / \mathrm{Al}, \mathrm{Mo} / \mathrm{Al}, \mathrm{Y} / \mathrm{Al}, \mathrm{B}_{4} \mathrm{C} / \mathrm{Al}$; however, only in very few cases the EUV reflectance of these structures are available in literature and, in general, they show very poor performance. Among the Albased structures, there are some structures that deserve further consideration. For instance, $\mathrm{Al} / \mathrm{SiC} \mathrm{ML}$ presents interesting results despite it has high roughness at the interfaces: in fact, the results achievable with this system are very similar to those of the $\mathrm{Mo} / \mathrm{Si}$ system in terms of EUV reflectance and superior in terms of spectral selectivity. ${ }^{82,83}$ At $30.4 \mathrm{~nm}$, the $\mathrm{Al} / \mathrm{Y}_{2} \mathrm{O}_{3}$ ML shows a reflectance of $24.9 \%$ while the standard $\mathrm{Mo} / \mathrm{Si}$ one of $21 \%$ in normal incidence. ${ }^{84}$ The experimental performance in the $17-19 \mathrm{~nm}$ spectral range are still missing in literature. 

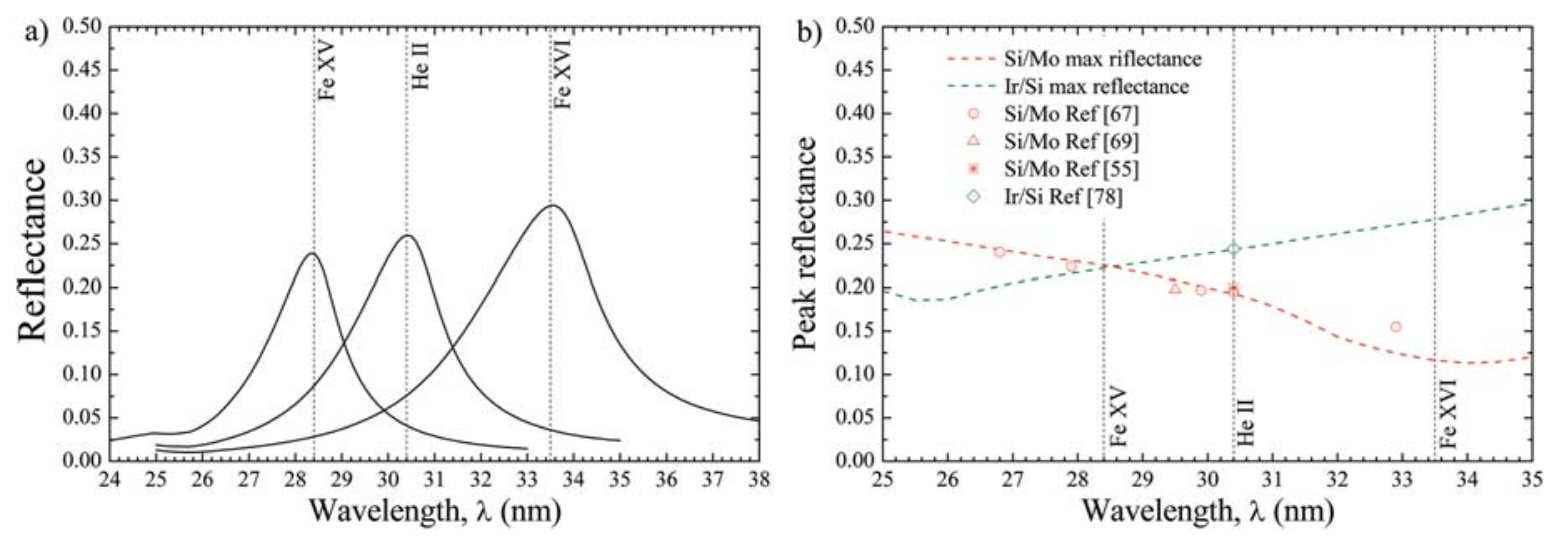

Figure 6. (a) Simulation of the spectral reflectance expected from an Ir/Si stack for the solar lines in the 25-35 nm spectral range; (b) comparison of the maximum reflectances expected from periodic $\mathrm{Mo} / \mathrm{Si}$ and $\mathrm{Ir} / \mathrm{Si}$ structures at each wavelength. For all simulations, the materials optical constants are those currently available in the CXRO website: ${ }^{70}$ for Si the optical constants are those provided in Ref. [71], for Mo are those provided in Ref. [72] (for wavelengths $>20.4 \mathrm{~nm}$ ) and Ref. [73] (for wavelengths $<20.4 \mathrm{~nm}$ ) while for Ir are those provided in Ref. [80]. In the Mo/Si structure the inter-diffusion at interfaces was modeled with an error function with $\sigma=0.6 \mathrm{~nm}$; in the case of the Ir/Si coating, the inter-diffusion was modeled considering an error function of $\sigma=1 \mathrm{~nm}$ for the Ir/a-Si interfaces and $\sigma=0.8 \mathrm{~nm}$ for the a-Si/Ir interfaces. ${ }^{78} \mathrm{In}$ the figure the experimental reflectance peaks reported in Refs. $[55,67,69,78]$ are shown as well.

The $\mathrm{Al} / \mathrm{Zr}$ system is perhaps the most promising Albased structure so far because of its native high EUV reflectance. ${ }^{85}$ Such coating has been suitably employed in the Hi-C sounding rocket experiment ${ }^{22}$ and for overcoating a prototype of a grating with ultra-high groove density. ${ }^{86}$ Additionally, such ML has been demonstrated to have good stability over time. ${ }^{87-89}$ Recent research has been oriented to develop techniques for further improving the $\mathrm{Al} / \mathrm{Zr}$ performance. The adoption of a $1 \% \mathrm{Si}$-doping $\mathrm{Al}$ layer was proposed for increasing the reflectance peak: ${ }^{88}$ this small concentration of Si highly affects the crystallization of both $\mathrm{Al}$ and $\mathrm{Zr}$ layers with a consequent decrease of the interface roughness. ${ }^{90}$ Moreover, this procedure seems to enhance the thermal stability as well. ${ }^{91,92}$ Alternatively, the $\mathrm{Al} / \mathrm{Zr}$ reflectance was enhanced by introducing Si barrier layers, with the aim to interrupt the Al layer crystallization and to reduce the roughness at the interfaces between the $\mathrm{Al}$ and $\mathrm{Zr}$ layers. ${ }^{93}$ In Figure 7 the peak reflectance expected with $\mathrm{Al}(1 \% \mathrm{wtSi}) / \mathrm{Zr}$ at different wavelengths is reported and compared with the experimental results available in literature.

Remarkable improvements were achieved by adopting Al-based tri-components periodic ML stacks. ${ }^{83,94-96}$ By opportunely choosing the materials, a system with smoother interfaces can be obtained. The best results in terms of the EUV reflectance and long-term stability were obtained both with $\mathrm{Al} / \mathrm{Mo} / \mathrm{SiC}^{97}$ and $\mathrm{Al} / \mathrm{Mo} / \mathrm{B}_{4} \mathrm{C}$ structures: the reflectance peaks of about $56 \%$ at $17.4 \mathrm{~nm}$ and about $50 \%$ at $21 \mathrm{~nm}$ were demonstrated to be stable over four years. ${ }^{95}$ Furthermore, $\mathrm{Al} / \mathrm{Mo} / \mathrm{B}_{4} \mathrm{C}$ reached a reflectance of $42 \%$ at $32 \mathrm{~nm} .{ }^{95}$ Such coatings showed a fair drop in reflectance after annealing of nearly 6 sweeks at $100{ }^{\circ} \mathrm{C}$ in air atmosphere, probably due to surface oxidation; ${ }^{95}$ in contrast, they remained stable after many vacuum thermal cycles ranging from $-50{ }^{\circ} \mathrm{C}$ up to $+70{ }^{\circ} \mathrm{C} .{ }^{96}$ In Figure 7 the peak reflectance expected with $\mathrm{Al} / \mathrm{Mo} / \mathrm{B}_{4} \mathrm{C}$ at each wavelength is reported and compared with the experimental results available in Ref. [95].

\subsection{Mg-Based EUV ML Structures}

Mg-based multilayers provide very high reflectance at EUV wavelengths longer than the $\mathrm{Mg} \mathrm{L}_{2,3}$-edge at about $25 \mathrm{~nm}$; such structures are very promising for telescopes making observations at the $\mathrm{Fe} \mathrm{XV}, \mathrm{He}$ II and Fe XVI solar plasma emission lines. Different $\mathrm{Mg}$ based MLs have been investigated, including $\mathrm{Mg} / \mathrm{Co}, \mathrm{Mg} / \mathrm{C}, \mathrm{Mg} / \mathrm{B}_{4} \mathrm{C}$, $\mathrm{Mg} / \mathrm{Si}$ and $\mathrm{Mg} / \mathrm{SiC} .{ }^{101-104}$ Among those, $\mathrm{Mg} / \mathrm{SiC}$ is one of the most promising because its theoretical reflectance approaches $60 \%$ at $30.4 \mathrm{~nm}$, with a spectral band of only $1.4 \mathrm{~nm}$ : in fact, in the $26-35 \mathrm{~nm}$ wavelength range, $\mathrm{Mg} / \mathrm{SiC}$ structure gives higher reflectance and narrower bandpass than both the standard Mo/Si and any other material pair. Furthermore, $\mathrm{Mg} / \mathrm{SiC}$ shows also a natively nearzero stress and a high thermal stability up to $350{ }^{\circ} \mathrm{C}$, definitely making this structure superior of any other material pairs in the $>25 \mathrm{~nm}$ wavelength region. ${ }^{45}$ However, the actual performance of $\mathrm{Mg} / \mathrm{SiC}$ are much lower than the theoretical predictions, achieving a reflectance peak of only $45 \%$ at $30.4 \mathrm{~nm} \cdot{ }^{101,104}$ This difference is due to the high chemical reactivity of the $\mathrm{Mg}$ which causes a prominent and asymmetrical inter-diffusion at the interfaces: the interlayer formed at the $\mathrm{Mg}$-on-SiC interfaces is about $1.0 \mathrm{~nm}$ thick while the one at the SiC-on-Mg is about $2.5 \mathrm{~nm} .{ }^{105,106} \mathrm{~A}$ simulation of the actual performance expected by a periodic $\mathrm{Mg} / \mathrm{SiC}$ stack is reported in Figure 8. Moreover, the $\mathrm{Mg} / \mathrm{SiC}$ system is also prone to catastrophic degradation, still due to the $\mathrm{Mg}$ chemical reactivity, which promotes corrosion mechanisms 

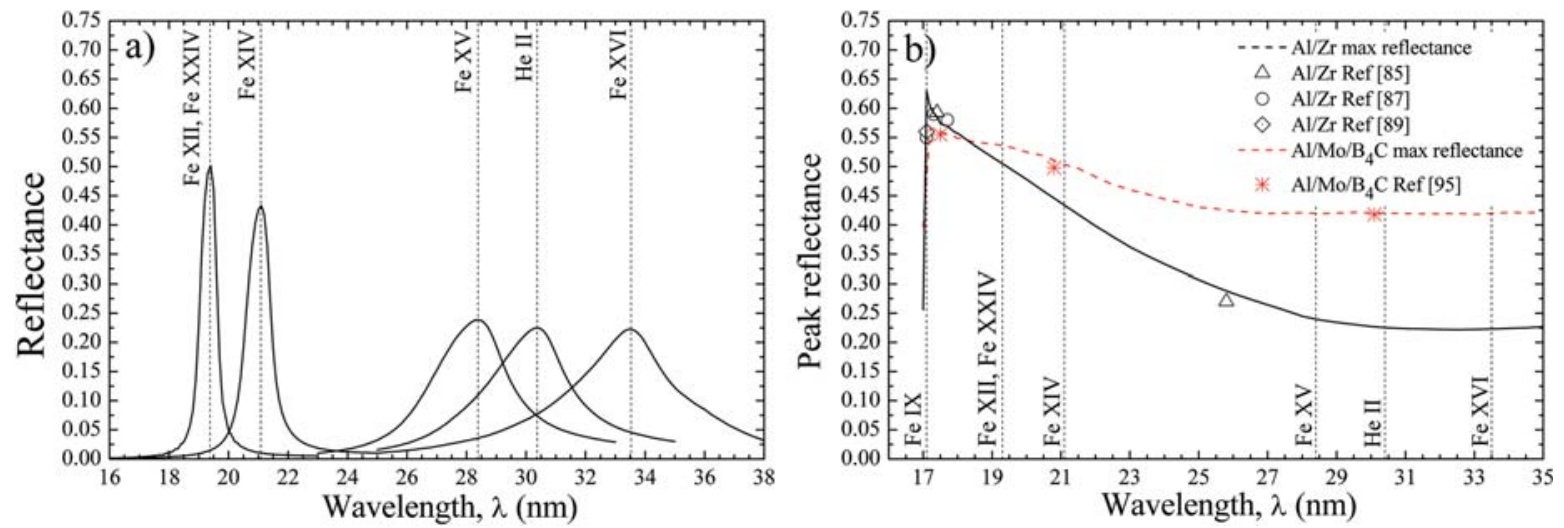

Figure 7. (a) Simulation of the spectral reflectance expected form $\mathrm{Al}(1 \% \mathrm{wtSi}) / \mathrm{Zr}$ stack for the solar lines in the 17-35 $\mathrm{nm}$ spectral band; (b) comparison of the maximum theoretical and experimental reflectance of periodic $\mathrm{Al}(1 \% \mathrm{wtSi}) / \mathrm{Zr}$ at $5^{\circ}$ incidence angle and of $\mathrm{Al} / \mathrm{Mo} / \mathrm{B}_{4} \mathrm{C}$ structures at $10^{\circ}$ incidence angle. ${ }^{85,87,89,95}$ In the simulations, the adopted optical constants of $\mathrm{Al}$, Mo and $\mathrm{Zr}$, were retrieved from the $\mathrm{CXRO}$ website ${ }^{70}$ : for $\mathrm{Al}$ the optical constants are those provided in Ref. [98], for Mo are those provided in Ref. [72] (for wavelengths $>20.4 \mathrm{~nm}$ ) and Ref. [73] (for wavelengths $<20.4 \mathrm{~nm}$ ), for $\mathrm{Zr}$ are those updated in $2010 .{ }^{99} \mathrm{The} \mathrm{Al}(1 \% \mathrm{wtSi})$ optical constants were computed from the atomic scattering factors of $\mathrm{Al}$ and $\mathrm{Si}^{71}$ available in CXRO website by considering a material density of $2.7 \mathrm{~g} / \mathrm{cm}^{3}$. For the $\mathrm{B}_{4} \mathrm{C}$, simulations used the optical constants provided in Ref. [100]. In the case of the $\mathrm{Al} / \mathrm{Zr}$ structure the inter-diffusion at interfaces was modeled with an error function with $\sigma=1.45 \mathrm{~nm}$; for the $\mathrm{Al} / \mathrm{Mo} / \mathrm{B}_{4} \mathrm{C} \mathrm{ML}$ an error function with $\sigma=0.85 \mathrm{~nm}$ was adopted.

on the surface. This process affected also the $\mathrm{Mg} / \mathrm{SiC}$ MLs selected to coat the EUV mirror of the telescopes of NASA's M-class SDO mission, ${ }^{68}$ which at the end were replaced with alternative coatings, resulting in a reduction of instrument light throughput by a factor of $10 .^{28}$ In order to overcome the $\mathrm{Mg}$ chemical reactivity, the use of $\mathrm{Al}$ corrosion barrier layers was proposed ${ }^{45,107} \mathrm{Al}$ layers of about $20 \mathrm{~nm}$ thickness were inserted above the topmost $\mathrm{Mg}$ layer and at the bottom of the multilayer, just on top of the Si substrate; over a short period of time ( $\sim$ weeks), the top and bottom $\mathrm{Al}-\mathrm{Mg}$ layers reacted to form a stable $\mathrm{Al}-\mathrm{Mg}$ alloy that appeared to be less susceptible to $\mathrm{Mg}$ corrosion, ${ }^{45}$ although the top Al layer slightly degraded the peak reflectance with respect to the standard $\mathrm{Mg} / \mathrm{SiC}$ system. Alternatively, it was demonstrated that the use of a 3-4 nm thick $\mathrm{SiC}$ capping-layer can slow down the degradation induced by the $\mathrm{Mg}$ corrosion, preserving good optical performances over 4 years. ${ }^{108}$ However, also this technique slightly degrades the maximum peak reflectance. An improvement of the optical performance of the $\mathrm{Mg} / \mathrm{SiC}$ structure can be obtained by using barrier-layers at each interface; in particular, it was demonstrated that the insertion of $\mathrm{Zr}$ barrier layers at the $\mathrm{SiC}$-on-Mg interfaces (much more inter-diffused than the $\mathrm{Mg}$-on-SiC ones) reduces their inter-diffusion width, improving the final reflectance peak up to $48 \%$ at $30.4 \mathrm{~nm}$ at $5^{\circ}$ incidence angle. ${ }^{109}$
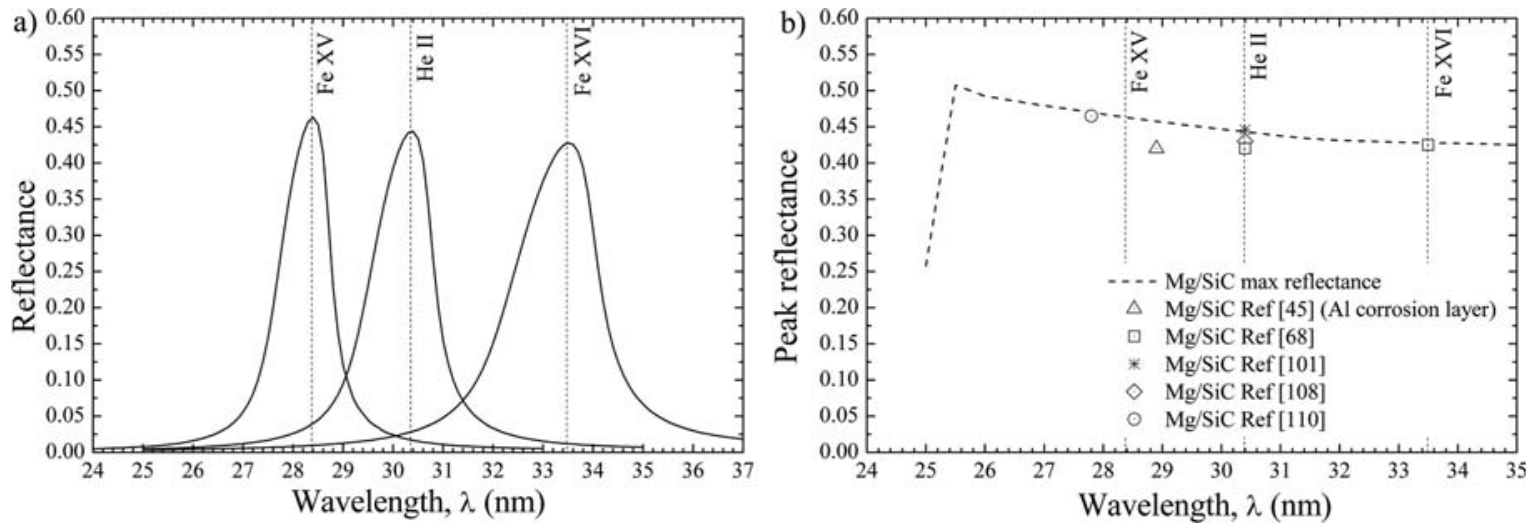

Figure 8. (a) Simulation of the spectral reflectance of the $\mathrm{Mg} / \mathrm{SiC}$ stack at different wavelengths in the 25-35 nm spectral range; (b) comparison of the maximum reflectance expected from periodic $\mathrm{Mg} / \mathrm{SiC}$ MLs working at $5^{\circ}$ of incidence angle at different wavelenghts. In the simulations, the materials optical constants are those currently available in the CXRO website ${ }^{70}$ : for Mg the optical constants are those provided in Ref. [111] while for $\mathrm{SiC}$ the optical constants were computed from the atomic scattering factors of $\mathrm{Si}^{71}$ and $\mathrm{C}^{80}$ by considering a material density of $3.11 \mathrm{~g} / \mathrm{cm}^{3}$. The inter-diffusion at interfaces was modeled with an error function with $\sigma=1.25 \mathrm{~nm}$ for the $\mathrm{Mg}$ on $\mathrm{SiC}$ interface and with $\sigma=2.2 \mathrm{~nm}$ for the SiC on $\mathrm{Mg}$ interface. In the figure the experimental reflectance peaks reported in Refs. [68, 101, 45, 108, 110] are reported as well. 
There are some alternative candidates to be used as high-reflective coatings at wavelength longer than the $\mathrm{Mg}$ $\mathrm{L}_{2,3}$ absorption edge. $\mathrm{Mg} / \mathrm{Co}$ offers still good EUV performance although lower than $\mathrm{Mg} / \mathrm{SiC}$ : it shows a peak reflectance of $40.3 \%$ at $30.5 \mathrm{~nm}$ when working at an incidence angle of $10^{\circ} .{ }^{101}$ An interesting result was instead achieved with a tri-materials structure: the $\mathrm{Mg} / \mathrm{Sc} / \mathrm{SiC}$ multilayer showed a peak reflectance of $52.8 \%$ at $28.4 \mathrm{~nm}$ with a FWHM bandwidth of $1.6 \mathrm{~nm}$ at near-normal incidence. ${ }^{10}$ As already occurred with Al-based MLs, trimaterial system seems to be a very promising solution for the Mg-based systems.

\subsection{Structures for Wavelength Shorter than Si $\mathbf{L}_{2,3}$ Absorption Edge}

The wavelength range $\lambda \sim 9-12 \mathrm{~nm}$ is of particular interest for solar physics due to the presence of the bright coronal Fe VIII line at $\lambda \sim 9.4 \mathrm{~nm}$ and other faint lines in the $10 \mathrm{~nm}-12 \mathrm{~nm}$ range. At wavelengths shorter than the $\mathrm{Si}$ $\mathrm{L}_{2,3}$-edge a number of efficient multilayer systems have been investigated. The Y-based MLs have demonstrated good EUV performances in the $\lambda \sim 8-12 \mathrm{~nm}$ range, since $\mathrm{Y}$ becomes a quite good spacer at wavelengths just longer than its $\mathrm{M}_{4,5}$ absorption edge (at about $7.95 \mathrm{~nm}$ ). Many structures were proposed, including $\mathrm{Y} / \mathrm{Ru}, \mathrm{Y} / \mathrm{Pd}, \mathrm{Y} / \mathrm{Ag}$, Y/Nb, Y/C. ${ }^{66,112,113}$ Among these, Y/Mo multilayer systems have shown a good stability, low stress and a relatively high peak in this spectral region, ${ }^{12,114}$ achieving a reflectance of 33-34\% near the diagnostically important Fe XVIII line at $\sim 9.4 \mathrm{~nm} .{ }^{66,115}$ For this reason, periodic Mo/Y multilayer coatings were employed in the $\mathrm{Fe}$ XVIII line imaging channels of AIA $^{28}$ onboard of SDO and SUVI $^{31}$ on the GOES-R satellite.
At these wavelengths, also B-based MLs can offer very high EUV performance. B has its $K$-edge at about $6.6 \mathrm{~nm}$, thus acting as good spacer in the $\lambda \sim 9-12 \mathrm{~nm}$ spectral range. $\mathrm{La} / \mathrm{B}_{4} \mathrm{C}$ and $\mathrm{La} / \mathrm{B}$ are the most promising MLs for the new generation of photolithographic mirrors since they can reach reflectance greater than $57 \%$ in the range 6.6-6.7 nm. ${ }^{116-118}$ Moreover, periodic and narrowband $\mathrm{Pd} / \mathrm{B}_{4} \mathrm{C}$ multilayers have been shown to have significantly higher peak reflectance (i.e., $43 \%$ ) than $\mathrm{Mo} / \mathrm{Y}$ at $9.1 \mathrm{~nm}$ wavelength, ${ }^{57}$ making this $\mathrm{ML}$ very interesting in solar physics applications. However, such coating undergoes extremely high stress ${ }^{87}$ and presents some stability issues. ${ }^{119}$ Nevertheless, this structure is still under investigation. It was found that the use of different materials as capping layers, such as Mo, can slow down the natural degradation occurring in $\mathrm{Pd} / \mathrm{B}_{4} \mathrm{C}$ films. ${ }^{120}$ Furthermore, a considerable reduction of the structure stress can be obtained by adding nitrogen in the atmosphere during the deposition process, although the reflectance loss is higher than $30 \% .{ }^{121}$ An alternative film characterized by a high theoretical reflectance in the $8-12 \mathrm{~nm}$ wavelength range is the Y/Pd stack. ${ }^{112}$ Unfortunately, in such structures the severe intermixing occurring between $\mathrm{Pd}$ and $Y$ layers results in an almost total disappearance of the interfaces inside the multilayer structures with a dramatic decrease of the reflectance. Nevertheless, it was recently demonstrated that by adding a small amount of nitrogen in the deposition atmosphere the intermixing at the interfaces can be reduced, obtaining a reflectance up to $30 \%$ at $9.3 \mathrm{~nm} .{ }^{122}$ A very promising result was instead obtained by adding a sub-nm-thick $\mathrm{B}_{4} \mathrm{C}$ barrier layer at each interface of a Y/Pd ML. ${ }^{123}$ Such structures provided higher reflectance at $9.4 \mathrm{~nm}$ (i.e., $43 \%$ with an incidence angle of $5^{\circ}$ ) and they do not suffer from the high stress found in
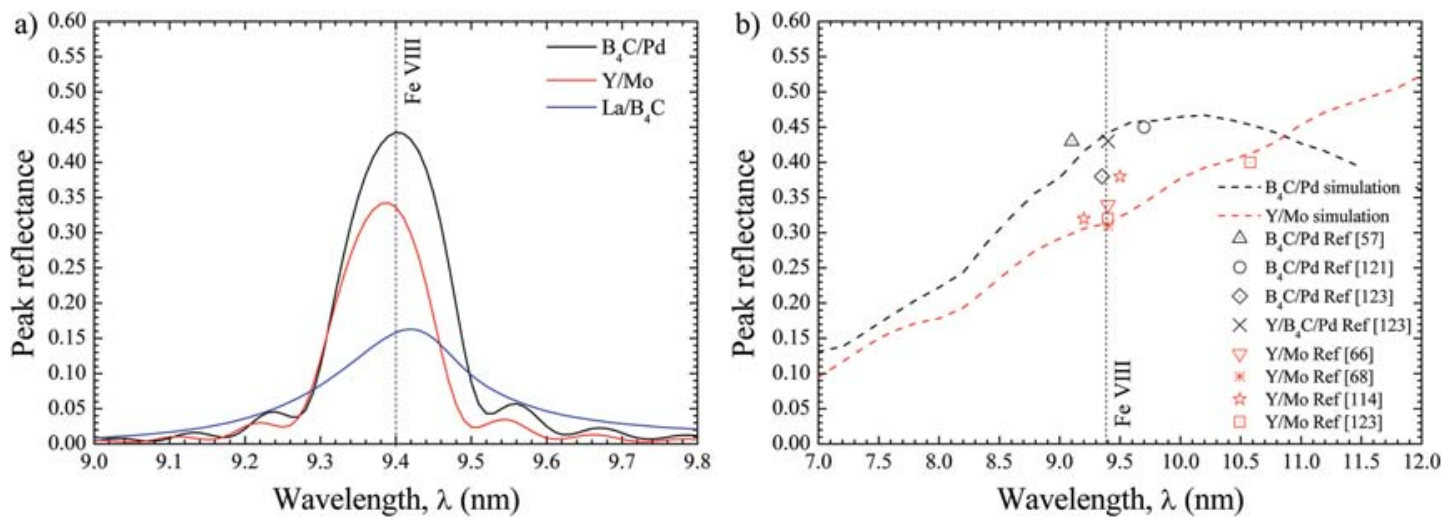

Figure 9. (a) Simulation of the spectral reflectance of the $\mathrm{Y} / \mathrm{Mo}, \mathrm{B}_{4} \mathrm{C} / \mathrm{Pd}$ and $\mathrm{La} / \mathrm{B}_{4} \mathrm{C}$ ML at the $\mathrm{Fe}$ VIII line $(\lambda \sim 9.4 \mathrm{~nm})$; (b) comparison of the maximum reflectance expected from periodic $\mathrm{Y} / \mathrm{Mo}$ and $\mathrm{B}_{4} \mathrm{C} / \mathrm{Pd} \mathrm{MLs}$ working at $5^{\circ}$ of incidence angle. In the simulations, the optical constants of the materials are those provided by $\mathrm{CXRO}^{70}$ : for Pd and $\mathrm{Y}$ the optical constants are those provided in Ref. [80] for La are those provided in Ref. [124] while for Mo are those provided in Ref. [73] For $\mathrm{B}_{4} \mathrm{C}$, simulations used the optical constants provided in Ref. [100]. In the case of La/ $\mathrm{B}_{4} \mathrm{C}$ MLs the inter-diffusion at interfaces was modeled with an error function with $\sigma=0.35 \mathrm{~nm}$ for the $\mathrm{B}_{4} \mathrm{C}$ on La interface and $\sigma=0.75 \mathrm{~nm}$ for the La on $\mathrm{B}_{4} \mathrm{C}$ interface. ${ }^{116}$ In the $\mathrm{B}_{4} \mathrm{C} / \mathrm{Pd} \mathrm{ML}$, an error function with $\sigma=0.65 \mathrm{~nm}$ was considered at each interface ${ }^{57}$ whereas for the Y/Mo ML an error function with $\sigma=0.57 \mathrm{~nm}$ was considered at each interface. ${ }^{36}$ 
the simple $\mathrm{Pd} / \mathrm{B}_{4} \mathrm{C}$ films. Furthermore, periodic $\mathrm{Pd} / \mathrm{B}_{4} \mathrm{C} / \mathrm{Y}$ MLs showed reasonably good temporal stability, with a measured drop in peak reflectance of about $10 \%$ over a period of 16 months. They are also thermally stable up to $100{ }^{\circ} \mathrm{C} .{ }^{123}$ In Figure 9(a), the expected performance of $\mathrm{Y} / \mathrm{Mo}, \mathrm{B}_{4} \mathrm{C} / \mathrm{Pd}$ and $\mathrm{La} / \mathrm{B}_{4} \mathrm{C}$ ML structure at $\mathrm{Fe}$ VIII line $(\lambda \sim 9.4 \mathrm{~nm})$ is reported; moreover, in Figure 9(b) the expected performance of $\mathrm{Y} / \mathrm{Mo}$ and $\mathrm{B}_{4} \mathrm{C} / \mathrm{Pd} \mathrm{ML}$ structures in the 7-12 $\mathrm{nm}$ wavelength range is reported and compared with the experimental results available in literature.

\section{STABILITY TO ACCELERATED IONS IMPLANTATION}

One of the main concerns in space optics regards the potential degradation occurring in components when they are exposed to the space environment. Harsh environmental agents can drastically affect the performance of the components, leading a change of the overall optical behavior of a space instrument; for this reason many efforts have been made over the years to study these degradation effects. ${ }^{125-128}$ In particular, the stability in harsh operational environment becomes more critical for the instruments onboard of Solar Orbiter mission because they will operate very close to the Sun. ${ }^{1}$ In this environment, the instruments undergo a constant bombardment of particles at different energies coming from different sources. ${ }^{129}$ For example, the quiet solar wind plasma is the main source of low energy particles, being mainly composed of protons and $\alpha$ particles having average energies of $1 \mathrm{keV}$ and $4 \mathrm{kev}$ respectively. Instead, occasional events such as coronal mass ejections and solar flares are sources of high energetic particles, giving protons and $\alpha$ particles with energies in the $\mathrm{MeV}$ range. Although the high energetic particles didn't show appreciable effects on EUV MLs, ${ }^{130}$ the particles at low energy can lead to a dramatic degradation of the performance, especially if the instrument layout foresees an unshielded ML primary mirror (an example of this class of instruments is the original layout of METIS coronagraph that was proposed for Solar Orbiter $\left.{ }^{131}\right)$. Recently, some ML structures were irradiated by low energy protons and $\alpha$-particles in order to assess their stability. ${ }^{61,62,96}$ In the experiment reported ${ }^{61} \mathrm{Mo} / \mathrm{Si}$ structures with different capping-layers were irradiated by protons at $1 \mathrm{keV}$ with doses equivalent to three months (i.e., $\sim 9 \cdot 10^{15} \mathrm{p} / \mathrm{cm}^{2}$ ) and one year (i.e., $\sim 36 \cdot 10^{15} \mathrm{p} / \mathrm{cm}^{2}$ ) operation of the Solar Orbiter spacecraft. After the irradiation with the one-year equivalent dose, all the tested structures showed a change of the peak position and a degradation of reflectance due to the blistering and delamination occurring in the topmost layers of the stack. Similar results were reported also in Refs.[132, 133]. However, these effects seem to be dependent on the material used for the capping-layer: in this experiment, all the Ir-capped ML showed a smaller reflectance loss and a shorter peak shift than the structures with other capping-layers. A similar result was obtained by irradiating such MLs with $4 \mathrm{keV}$ $\mathrm{He}^{+}$ions, where the Ir-capped MLs showed the smallest degradation. ${ }^{62}$ After $\mathrm{He}^{+}$ion irradiation with doses equivalent to one year (i.e., $\sim 2.5 \cdot 10^{15} \mathrm{p} / \mathrm{cm}^{2}$ ), two years (i.e., $\sim 5 \cdot 10^{15} \mathrm{p} / \mathrm{cm}^{2}$ ) and four years (i.e., $\sim 10^{16} \mathrm{p} / \mathrm{cm}^{2}$ ) operation of the Solar Orbiter spacecraft, the exposed MLs show a drop of reflectance and no appreciable reflectance peak shifts; this behavior was attributed to an increase of the intermixing at interfaces induced by the $\mathrm{He}^{+}$ions in the topmost layers. Recently, $\mathrm{Al} / \mathrm{Mo} / \mathrm{B}_{4} \mathrm{C}$ and $\mathrm{Al} / \mathrm{Mo} / \mathrm{SiC}$ were also irradiated with low energy $(1 \mathrm{keV})$ and high energy $(100 \mathrm{keV})$ protons ${ }^{96}$ with doses of $7.4 \cdot 10^{12} \mathrm{p} / \mathrm{cm}^{2}$ and $9 \cdot 10^{15} \mathrm{p} / \mathrm{cm}^{2}$; the lowest dose was chosen in order to simulate the situation expected inside the High Resolution Imager (HRI) and Full Sun Imager (FSI) telescopes of Solar Orbiter mission, where the mechanical structure and the front filters drastically reduce the proton flux impinging on the multilayers. All the structures irradiated didn't show appreciable changes of their performance, suggesting that at these doses MLs can be considered stable.

\section{CONCLUSIONS}

In the present paper the ML coating nanostructures developed so far and applied to observations of solar plasma emission lines in the $6 \mathrm{~nm}-35 \mathrm{~nm}$ wavelength range have been reviewed. After a briefly recall of ML theory, a detailed discussion of the most promising material pairs and layer structures proposed and applied to past and current space missions is presented. Finally, recent experiments performed in order to assess ML stability to low energy ion bombardment have been reported.

\section{References and Notes}

1. D. Müller, R. G. Marsden, O. C. St. Cyr, and H. R. Gilbert, Solar Physics 285, 25 (2013).

2. J. T. Karpen, Why do we need high-resolution observations of the Sun? Proc. SPIE 4853, Innovative Telescopes and Instrumentation for Solar Astrophysics, Waikoloa, HI, USA (2003), p. 453.

3. E. Spiller, Soft X-ray Optics, SPIE Press, Bellingham, WA (1994)

4. E. Spiller, Appl. Phys. Lett. 20, 365 (1972).

5. D. L. Windt, Computers in Physics 12, 360 (1998).

6. J. H. Underwood, M. E. Bruner, and W. Haisch, Science 238, 61 (1987).

7. A. Walker, J. Lindblom, T. Barbee, and R. Hoover, Science 241, 1781 (1988).

8. J. F. Lindblom, A. B. Walker, R. B. Hoover, T. W. Barbee, R. A. VanPatten, and J. P. Gill, Soft X-ray/extreme ultraviolet images of the solar atmosphere with normal incidence multilayer optics, Proc. SPIE 0982, X-ray Instrumentation in Astronomy II, San Diego, CA, USA (1988), p. 316.

9. L. Golub, M. Herant, K. Kalata, I. Lovas, G. Nystrom, E. Spiller, and J. Wilcyznski, Nature 344, 842 (1990).

10. A. B. C. Walker, J. F. Lindblom, R. H. O'Neal, M. J. Allen, T. W J. Barbee, and R. B. Hoover, Optical Engineering 29, 581 (1990).

11. R. A. M. Keski-Kuha, R. J. Thomas, and J. M. Davila, Rocket flight of a multilayer-coated high-density EUV toroidal grating, Proc. SPIE 1546, Multilayer and Grazing Incidence X-ray/EUV Optics, San Diego, CA, USA (1992), p. 614.

12. D. M. Cotton, R. A. Conant, and Supriya Chakrabarti, Opt. Eng. 32, 3170 (1993). 
13. A. B. C. Walker II, M. J. Allen, C. E. DeForest, C. C. Kankelborg, D. S. Martinez-Galarce, J. E. Plummer, R. B. Hoover, J. Troy W. Barbee, and D. B. Gore, Multi-spectral solar telescope array VIII: The second flight, Proc. SPIE 2515, X-ray and Extreme Ultraviolet Optics, San Diego, CA, USA (1995), p. 182.

14. T. Sakao, S. Tsuneta, H. Hara, R. Kano, T. Yoshida, S. Nagata, T. Shimizu, T. Kosugi, K. Murakami, W. Wasa, M. Inoue, K. Miura, $\mathrm{K}$. Taguchi, and K. Tanimoto, Japanese sounding rocket experiment with the solar XUV Doppler telescope, Proc. SPIE 2804, Missions to the Sun, Denver, CO, USA (1996), p. 153.

15. I. Yoshikawa, M. Nakamura, M. Hirahara, Y. Takizawa, K. Yamashita, H. Kunieda, T. Yamazaki, K. Misaki, and A. Yamaguchi, Journal of Geophysical Research: Space Physics 102, 19897 (1997).

16. J. S. Newmark, J. D. Moses, J. W. Cook, J.-P. Delaboudiniere, X. Song, C. Carabetian, M. Bougnet, J. Brunaud, J.-M. Defise, F. Clette, and J.-F. E. Hochedez, Calibration and flight of the NRL EIT CalRoc, Proc. SPIE 4139, Instrumentation for UV/EUV Astronomy and Solar Missions, San Diego, CA, USA (2000), p. 328.

17. D. S. Martınez-Galarce, A. B. C. Walker II, D. B. Gore, C. C. Kankelborg, R. B. Hoover, T. W. Barbee Jr., and P. F. X. Boerner, Optical Engineering 39, 1063 (2000).

18. F. Auchère, D. M. Hassler, D. C. Slater, and T. N. Woods, Solar Physics 202, 269 (2001).

19. J. W. Brosius, D. M. Rabin, and R. J. Thomas, The Astrophysical Journal Letters 656, L41 (2007).

20. J. L. Fox, C. C. Kankelborg, and R. J. Thomas, The Astrophysical Journal 719, 1132 (2010).

21. J. Newmark, J. Moses, E. Antonucci, S. Fineschi, L. Abbo, D. Telloni, F. Auchere, N. Barbey, and M. Romoli, HERSCHEL sounding rocket mission observations of the helium corona, American Astronomical Society, AAS Meeting \#216, id.407.21.

22. K. Kobayashi, J. Cirtain, A. R. Winebarger, K. Korreck, L. Golub, R. W. Walsh, B. De Pontieu, C. DeForest, A. Title, S. Kuzin, S. Savage, D. Beabout, B. Beabout, W. Podgorski, D. Caldwell, K. McCracken, M. Ordway, H. Bergner, R. Gates, S. McKillop, P. Cheimets, S. Platt, N. Mitchell, and D. Windt, Solar Physics 289, 4393 (2014).

23. F. Auchère, M.-F. Ravet-Krill, J. D. Moses, F. Rouesnel, J.-P. Moalic, D. Barbet, C. Hecquet, A. Jérome, R. Mercier, J.-C. Leclec'h, F. Delmotte, and J. S. Newmark, HECOR: A HElium CORonagraphy aboard the Herschel sounding rocket, Proc. SPIE 6689, Solar Physics and Space Weather Instrumentation II, San Diego, CA, USA (2007), p. 66890A.

24. J. Delaboudinière, G. Artzner, J. Brunaud, A. H. Gabriel, J. Hochedez, F. Millier, X. Song, B. Au, K. P. Dere, R. Howard, R. Kreplin, D. Michels, J. Moses, J. M. Defise, C. Jamar, and P. Rochus, Solar Physics 162, 291 (1995).

25. B. N. Handy, L. W. Acton, C. C. Kankelborg, C. J. Wolfson, D. J Akin, M. E. Bruner, R. Caravalho, R. C. Catura, R. Chevalier, D. W. Duncan, C. G. Edwards, C. N. Feinstein, S. L. Freeland, F. M. Friedlaender, C. H. Hoffmann, N. E. Hurlburt, B. K. Jurcevich, N. L. Katz, G. A. Kelly, J. R. Lemen, M. Levay, R. W. Lindgren, D. P. Mathur, S. B. Meyer, S. J. Morrison, M. D. Morrison, R. W. Nightingale, T. P. Pope, R. A. Rehse, C. J. Schrijver, R. A. Shine, L. Shing, K. T. Strong, T. D. Tarbell, A. M. Title, D. D. Torgerson, L. Golub, J. A. Bookbinder, D. Caldwell, P. N. Cheimets, W. N. Davis, E. E. Deluca, R. A. McMullen, H. P. Warren, D. Amato, R. Fisher, H. Maldonado, and C. Parkinson, Solar Physics 187, 229 (1999).

26. J.-P. Wuelser, J. R. Lemen, T. D. Tarbell, C. J. Wolfson, J. C. Cannon, B. A. Carpenter, D. W. Duncan, G. S. Gradwohl, S. B. Meyer, A. S. Moore, R. L. Navarro, J. D. Pearson, G. R. Rossi, L. A. Springer, R. A. Howard, J. D. Moses, J. S. Newmark, J.-P. Delaboudiniere, G. E. Artzner, F. Auchere, and B. Marie, EUVI: The STEREO-SECCHI extreme ultraviolet imager, Proc.
SPIE 5171, Telescopes and Instrumentation for Solar Astrophysics, San Diego, California, USA (2004).

27. J. L. Culhane, L. K. Harra, A. M. James, K. Al-Janabi, L. J. Bradley, R. A. Chaudry, K. Rees, J. A. Tandy, P. Thomas, M. C. R. Whillock, B. Winter, G. A. Doschek, C. M. Korendyke, C. M. Brown, S. Myers, J. Mariska, J. Seely, et. al., Solar Physics 243, 19 (2007).

28. J. R. Lemen, A. M. Title, D. J. Akin, P. F. Boerner, C. Chou, J. F. Drake, D. W. Duncan, C. G. Edwards, F. M. Friedlaender, G. F. Heyman, N. E. Hurlburt, N. L. Katz, G. D. Kushner, M. Levay, R. W. Lindgren, D. P. Mathur, E. L. McFeaters, S. Mitchell, R. A. Rehse, C. J. Schrijver, L. A. Springer, R. A. Stern, T. D. Tarbell, J.-P. Wuelser, C. J. Wolfson, C. Yanari, J. A. Bookbinder, P. N. Cheimets, D. Caldwell, E. E. Deluca, R. Gates, L. Golub, S. Park, W. A. Podgorski, R. I. Bush, P. H. Scherrer, M. A. Gummin, P. Smith, G. Auker, P. Jerram, P. Pool, R. Soufli, D. L. Windt, S. Beardsley, M. Clapp, J. Lang, and N. Waltham, Solar Physics 275, 17 (2012).

29. D. B. Seaton, D. Berghmans, B. Nicula, J.-P. Halain, A. De Groof, T. Thibert, D. S. Bloomfield, C. L. Raftery, P. T. Gallagher, F. Auchère, J.-M. Defise, E. D'Huys, J.-H. Lecat, E. Mazy, P. Rochus, L. Rossi, U. Schühle, V. Slemzin, M. S. Yalim, and J. Zender, Solar Physics 286, 43 (2013).

30. V. A. Slemzin, S. V. Kuzin, I. A. Zhitnik, J.-P. Delaboudiniere, F. Auchere, A. N. Zhukov, R. Van der Linden, O. I. Bugaenko, A. P. Ignat'ev, A. V. Mitrofanov, A. A. Pertsov, S. N. Oparin, A. I. Stepanov, and A. N. Afanas'ev, Solar System Research 39, 489 (2005).

31. D. Martínez-Galarce, R. Soufli, D. L. Windt, M. Bruner, E. Gullikson, S. Khatri, E. Spiller, J. C. Robinson, S. Baker, and E. Prast, Opt. Eng. 52, 095102 (2013).

32. S. V. Kuzin, I. A. Zhitnik, S. V. Shestov, S. A. Bogachev, O. I. Bugaenko, A. P. Ignat'ev, A. A. Pertsov, A. S. Ulyanov, A. A. Reva, V. A. Slemzin, N. K. Sukhodrev, Yu. S. Ivanov, L. A. Goncharov, A. V. Mitrofanov, S. G. Popov, T. A. Shergina, V. A. Solov'ev, S. N. Oparin, and A. M. Zykov, Solar System Research 45, 162 (2011).

33. I. Yoshikawa, A. Yamazaki, G. Murakami, K. Yoshioka, S. Kameda, F. Ezawa, T. Toyota, W. Miyake, M. Taguchi, M. Kikuchi, and M. Nakamura, Earth, Planets and Space 60, 407 (2008).

34. J.-P. Halain, P. Rochus, E. Renotte, F. Auchère, D. Berghmans, L. Harra, U. Schühle, W. Schmutz, A. Zhukov, R. Aznar Cuadrado, F. Delmotte, C. Dumesnil, M. Gyo, T. Kennedy, R. Mercier, F. Verbeeck, M. Thome, K. Heerlein, A. Hermans, L. Jacques, A. Mazzoli, S. Meining, L. Rossi, J. Tandy, P. Smith, and B. Winter, The extreme UV imager of solar orbiter: From detailed design to flight model, Proc. SPIE 9144, Space Telescopes and Instrumentation 2014: Ultraviolet to Gamma Ray, Montréal, Quebec, Canada (2014), p. 914408.

35. T. Sakao, N. Narukage, S. Imada, Y. Suematsu, M. Shimojo, S. Tsuneta, E. E. DeLuca, K. Watanabe, and S.-N. Ishikawa, The $\mathrm{X}$-ray/EUV telescope for the Solar-C mission: Science and development activities, Proc. SPIE 8443, Space Telescopes and Instrumentation 2012: Ultraviolet to Gamma Ray, Amsterdam, NL (2012), p. 84430 A.

36. A. J. Corso, P. Zuppella, E. Principi, E. Giangrisostomi, F. Bencivenga, A. Gessini, S. Zuccon, C. Masciovecchio, A. Giglia, S. Nannarone, and M. G. Pelizzo, Journal of Optics 17, 025505 (2015).

37. D. Attwood and A. Sakdinawat, X-rays and Extreme Ultraviolet Radiation: Principles and Applications, Cambridge University Press, Cambridge, UK (2016).

38. J. F. Seely, C. M. Brown, D. L. Windt, S. Donguy, and B. Kjornrattanawanich, Appl. Opt. 43, 1463 (2004).

39. A. S. Morlens, P. Balcou, P. Zeitoun, C. Valentin, V. Laude, and S. Kazamias, Opt. Lett. 30, 1554 (2005). 
40. A. L. Aquila, F. Salmassi, F. Dollar, Y. Liu, and E. M. Gullikson, Opt. Express 14, 10073 (2006).

41. M. Suman, F. Frassetto, P. Nicolosi, and M. G. Pelizzo, Appl. Opt. 46, 8159 (2007).

42. E. M. Gullikson, C. N. Anderson, S. S. Kim, D. Lee, R. Miyakawa, F. Salmassi, and P. P. Naulleau, Appl. Opt. 54, 4280 (2015).

43. S. Braun, H. Mai, M. Moss, R. Scholz, and A. Leson, Jpn. J. Appl. Phys. 41, 4074 (2002).

44. J. Zhu, S. Zhou, H. Li, Z. Wang, P. Jonnard, K. Le Guen, M. H. Hu, J. M. André, H. Zhou, and T. Huo, Opt. Express 19, 21849 (2011).

45. R. Soufli, M. Fernandez-Perea, S. L. Baker, J. C. Robinson, J. Alameda, and C. C. Walton, Appl. Phys. Lett. 101, 043111 (2012).

46. V. I. T. A. de Rooij-Lohmann, L. W. Veldhuizen, E. Zoethout, A. E. Yakshin, R. W. E. van de Kruijs, B. J. Thijsse, M. Gorgoi, F. Schäfers, and F. Bijkerk, J. Appl. Phys. 108, 094314 (2010).

47. J. Bosgra, L. W. Veldhuizen, E. Zoethout, J. Verhoeven, R. A. Loch, A. E. Yakshin, and F. Bijkerk, Thin Solid Films 542, 210 (2013).

48. J. I. Larruquert, J. Opt. Soc. Am. A 19, 391 (2002).

49. J. Gautier, F. Delmotte, M. Roulliay, F. Bridou, M. F. Ravet, and A. Jerome, Appl. Opt. 44, 384 (2005).

50. A. BenMoussa, S. Gissot, U. Schühle, G. Del Zanna, F. Auchère, S. Mekaoui, A. R. Jones, D. Walton, C. J. Eyles, G. Thuillier, D. Seaton, I. E. Dammasch, G. Cessateur, M. Meftah, V. Andretta, D. Berghmans, D. Bewsher, D. Bolsée, L. Bradley, D. S. Brown, P. C. Chamberlin, S. Dewitte, L. V. Didkovsky, M. Dominique, F. G. Eparvier, T. Foujols, D. Gillotay, B. Giordanengo, J. P. Halain, R. A. Hock, A. Irbah, C. Jeppesen, D. L. Judge, M. Kretzschmar, D. R. McMullin, B. Nicula, W. Schmutz, G. Ucker, S. Wieman, D. Woodraska, and T. N. Woods, Solar Physics 288, 389 (2013).

51. F. Eggenstein, F. Senf, T. Zeschke, and W. Gudat, Nucl. Instr. Meth. Phys. Res. A 467-468, 325 (2001).

52. E. Gubbini, G. Kommol, M. Schnurer, H. Schonagel, U. Eichmann, M. P. Kalashnikov, P. V. Nickles, F. Eggenstein, G. Reichardt, and W. Sandner, Vacuum 76, 45 (2004).

53. S. Bajt, H. N. Chapman, N. Nguyen, J. Alameda, J. C. Robinson, M. Malinowski, E. Gullikson, A. Aquila, C. Tarrio, and S. Grantham, Appl. Opt. 42, 5750 (2003).

54. S. Bajt, N. V. Edwards, and T. E. Madey, Surface Science Reports 63, 73 (2008).

55. A. J. Corso, P. Zuppella, P. Nicolosi, D. L. Windt, E. Gullikson, and M. G. Pelizzo, Opt. Express 19, 13963 (2011).

56. M. G. Pelizzo, A. J. Corso, G. Monaco, P. Nicolosi, M. Suman, P. Zuppella, and D. Cocco, Nucl. Instr. Meth. Phys. Res. A 635, S24 (2011).

57. A. J. Corso, P. Zuppella, D. L. Windt, M. Zangrando, and M. G. Pelizzo, Opt. Express 20, 8006 (2012).

58. P. Naujok, S. Yulin, A. Bianco, N. Mahne, N. Kaiser, and A. Tünnermann, Opt. Express 23, 4289 (2015).

59. M. Suman, M. G. Pelizzo, D. L. Windt, and P. Nicolosi, Appl. Opt. 48, 5432 (2009).

60. M. G. Pelizzo, S. Fineschi, P. Zuppella, A. J. Corso, D. L. Windt, and P. Nicolosi, SiC/Mg multilayer coatings for SCORE coronagraph: Long term stability analysis, Proc. SPIE 8148, Solar Physics and Space Weather Instrumentation IV, San Diego, CA, USA (2011), p. 81480M.

61. M. G. Pelizzo, A. J. Corso, P. Zuppella, D. L. Windt, G. Mattei, and P. Nicolosi, Opt. Express 19, 14838 (2011).

62. M. Nardello, P. Zuppella, V. Polito, A. J. Corso, S. Zuccon, and M. G. Pelizzo, Opt. Express 21, 28334 (2013).

63. T. W. Barbee, S. Mrowka, and M. C. Hettrick, Appl. Opt. 24,883 (1985).

64. J. A. Folta, S. Bajt, T. W. Barbee Jr., R. F. Grabner, P. B. Mirkarimi, T. Nguyen, M. A. Schmidt, E. Spiller, C. C. Walton, M. Wedowski, and C. Montcalm, Multilayer reflective coatings for extreme-ultraviolet lithography, Proc. SPIE 3676, Emerging Lithographic Technologies II, Santa Clara, CA, USA (1999), p. 702.

65. E. Louis, A. E. Yakshin, P. C. Goerts, S. Oestreich, R. Stuik, E. L. G. Maas, M. J. H. Kessels, F. Bijkerk, M. Haidl, S. Muellender, M. Mertin, D. Schmitz, F. Scholze, and G. Ulm, Progress in Mo/Si multilayer coating technology for EUVL optics, Proc. SPIE 3997, Emerging Lithographic Technologies IV, Santa Clara, CA, USA (2000), p. 406.

66. D. L. Windt, S. Donguy, J. Seely, B. Kjornrattanawanich, E. M Gullikson, C. C. Walton, L. Golub, and E. DeLuca, EUV multilayers for solar physics, Proc. SPIE 5168, Optics for EUV, X-ray, and Gamma-Ray Astronomy 1, San Diego, CA, USA (2004), p. 1.

67. D. L. Windt, S. Donguy, J. Seely, and B. Kjornrattanawanich, Appl. Opt. 43, 1835 (2004)

68. R. Soufli, D. L. Windt, J. C. Robinson, S. L. Baker, E. Spiller, F. J. Dollar, A. L. Aquila, E. M. Gullikson, B. Kjornrattanawanich, J. F. Seely, and L. Golub, Development and testing of EUV multilayer coatings for the atmospheric imaging assembly instrument aboard the solar dynamics observatory, Proc. SPIE 5901, Solar Physics and Space Weather Instrumentation, San Diego, CA (2005), p. 59010M.

69. Z. Wang, J. Zhu, Z. Zhang, X. Cheng, J. Xu, F. Wang, X. Wang, and L. Chen, Development of multilayer optics in EUV, soft X-ray and X-ray range at IPOE, edited by C. L. S. Lewis and D. Riley, X-ray Lasers 2008, Springer Proceedings in Physics, Springer, Dordrecht (2009), Vol. 130.

70. http://cxro. lbl.gov/, last access in December (2017).

71. R. Soufli and E. M. Gullikson, Appl. Opt. 36, 5499 (1997).

72. C. Tarrio, R. N. Watts, T. B. Lucatorto, J. M. Slaughter, and C. M. Falco, Appl. Opt. 37, 4100 (1998).

73. R. Soufli and E. M. Gullikson, Appl. Opt. 37, 1713 (1998).

74. M. G. Pelizzo, A. J. Corso, P. Zuppella, and P. Nicolosi, Nucl. Instr. Meth. Phys. Res. A 720, 49 (2013).

75. J.-P. Chauvineau, J.-Y. Clotaire, G. Colas, O. Lam, J.-C Manneville, J.-P. Marioge, M. Mullot, A. Raynal, G. Tissot, L. Valiergue, and J.-P. Delaboudiniere, Description and performance of mirrors and multilayers for the extreme ultraviolet imaging telescope of the SOHO mission, Proc. SPIE 1546, Multilayer and Grazing Incidence X-ray/EUV Optics, San Diego, CA, USA (1992), p. 576.

76. T. Feigl, S. Yulin, T. Kuhlmann, and N. Kaiser, Japanese Journal of Applied Physics 41, 6B (2002).

77. T. Feigl, H. Lauth, S. Yulin, and N. Kaiser, Microelectron. Eng. 57-58, 3 (2001).

78. P. Zuppella, G. Monaco, A. J. Corso, P. Nicolosi, D. L. Windt, V. Bello, G. Mattei, and M. G. Pelizzo, Opt. Lett. 36, 1203 (2011).

79. S. Bajt, J. B. Alameda, T. W. Barbee, W. Miles Clift, J. A. Folta, B. B. Kaufmann, and E. A. Spiller, Improved reflectance and stability of Mo/Si multilayers, Proc. SPIE 4506, Soft X-ray and EUV Imaging Systems II, San Diego, CA, USA (2001), p. 65.

80. B. L. Henke, E. M. Gullikson, and J. C. Davis, Atomic Data and Nuclear Data Tables 54, 181 (1993).

81. H. Okamoto, J. Phase Equilibria 23, 455 (2002).

82. D. L. Windt and J. A. Bellotti, Appl. Opt. 48, 4932 (2009).

83. E. Meltchakov, C. Hecquet, M. Roulliay, S. De Rossi, Y. Menesguen, A. Jérome, F. Bridou, F. Varniere, M. F. Ravet-Krill, and F. Delmotte, Appl. Phys. A 98, 111-117 (2010).

84. G. Murakami, K. Sakai, T. Homma, K. Yoshioka, I. Yoshikawa, S Ichimaru, and H. Takenaka, Rev. Sci. Instrum. 82, 033106 (2011).

85. PXRMS multilayer survey results $\mathrm{Zr} / \mathrm{Al}$ : http://www.cxro.lbl gov/multilayer/survey.html.

86. D. L. Voronov, E. H. Anderson, R. Cambie, S. Cabrini, S. D. Dhuey, L. I. Goray, E. M. Gullikson, F. Salmassi, T. Warwick, V. V. Yashchuk, and H. A. Padmore, Opt. Express 19, 6320 (2011).

87. D. L. Windt, EUV multilayer coatings for solar imaging and spectroscopy, Proc. SPIE 9604, Solar Physics and Space Weather Instrumentation VI, San Diego, CA, USA (2015), p. 96040P-1. 
88. Q. Zhong, W. Li, Z. Zhang, J. Zhu, Q. Huang, H. Li, Z. Wang, P. Jonnard, K. L. Guen, J.-M. André, H. Zhou, and T. Huo, Opt. Express 20, 10692 (2012).

89. S. A. Bogachev, N. I. Chkhalo, S. V. Kuzin, D. E. Pariev, V. N Polkovnikov, N. N. Salashchenko, S. V. Shestov, and S. Y. Zuev, Appl. Opt. 55, 2126 (2016).

90. Q. Zhong, Z. Zhang, J. T. Zhu, Z. S. Wang, P. Jonnard, K. Le Guen, and J.-M. André, Appl. Surf. Sci. 259, 371 (2012).

91. Q. Zhong, Z. Zhang, J. T. Zhu, Z. S. Wang, P. Jonnard, K. Le Guen, Y. Y. Yuan, J.-M. André, H. J. Zhou, and T. L. Huo, Appl. Phys. A: Mater. Sci. Process. 109, 133 (2012)

92. Q. Zhong, Z. Zhang, W. Li, J. Zhu, Z. Wang, P. Jonnard, K. L. Guen, Y. Yuan, J.-M. André, H. Zhou, and T. Huo, Journal of Physics: Conference Series 425, 152010 (2013).

93. Q. Zhong, Z. Zhang, R. Qi, J. Li, Z. Wang, K. L. Guen, J.-M. André, and P. Jonnard, Opt. Express 21, 14399 (2013).

94. E. Meltchakov, A. Ziani, F. Auchere, X. Zhang,M. Roulliay, S. De Rossi, Ch. Bourassin-Bouchet, A. Jérome, F. Bridou, F. Varniere, and F. Delmotte, EUV reflectivity and stability of tri-component Al-based multilayers, Proc. SPIE 8168, Advances in Optical Thin Films IV, Marseille, FR (2011), p. 816819.

95. E. Meltchakov, S. De Rossi, R. Mercier, F. Varniere, A. Jérome, F. Auchere, X. Zhang, M. Roulliay, and F. Delmotte, Single and multi-channel Al-based multilayer systems for space applications in EUV range, Proc. SPIE 8777, Damage to VUV, EUV, and X-ray Optics IV; and EUV and X-ray Optics: Synergy between Laboratory and Space III, Prague, CZ (2013), p. 87771C.

96. F. Delmotte, E. Meltchakov, S. de Rossi, F. Bridou, A. Jérome, F. Varnière, R. Mercier, F. Auchère, X. Zhang, B. Borgo, C. Dumesnil, S. François, M. Roulliay, and U. Strauch, Development of multilayer coatings for solar orbiter EUV imaging telescopes, Proc. SPIE 8862, Solar Physics and Space Weather Instrumentation V, San Diego, CA, USA (2013), p. 88620A

97. M. H. Hu, K. Le Guen, J. M. André, P. Jonnard, E. Meltchakov, F. Delmotte, and A. Galtayries, Opt. Exp. 18, 20019 (2010).

98. E. M. Gullikson, P. Denham, S. Mrowka, and J. H. Underwood, Physical Review B 49, 16283 (1994).

99. http://henke. lbl.gov/optical_constants/update.html (last access in December 2017).

100. R. Soufli, A. L. Aquila, F. Salmassi, M. Fernández-Perea, and E. M. Gullikson, Appl. Opt. 47, 4633 (2008).

101. J. Zhu, S. Zhou, H. Li, Q. Huang, Z. Wang, K. L. Guen, M.-H. Hu, J.-M. André, and P. Jonnard, Appl. Opt. 49, 3922 (2010).

102. T. Ejima, A. Yamazaki, T. Banse, K. Saito, Y. Kondo, S. Ichimaru, and H. Takenaka, Appl. Opt. 44, 5446 (2005).

103. J. Zhu, Z. Wang, Z. Zhang, F. Wang, H. Wang, W. Wu, S. Zhang, D. Xu, L. Chen, H. Zhou, T. Huo, M. Cui, and Y. Zhao, Appl. Opt. 47, C310 (2008).

104. I. Yoshikawa, T. Murachi, H. Takenaka, and S. Ichimaru, Rev. Sci. Inst. 76, 066109 (2005).

105. H. Li, J. Zhu, Z. Wang, Z. Song, and H. Chen, Opt. Mater. Express 3, 546 (2013)

106. H. Maury, P. Jonnard, K. Le Guen, J.-M. André, Z. Wang, J. Zhu, J. Dong, Z. Zhang, F. Bridou, F. Delmotte, C. Hecquet, N. Mahne, A. Giglia, and S. Nannarone, Eur. Phys. J. B 64, 193 (2008).

107. M. Fernández-Perea, R. Soufli, J. C. Robinson, L. Rodríguez De Marcos, J. A. Méndez, J. I. Larruquert, and E. M. Gullikson, Opt. Express 20, 24018 (2012).

108. M. G. Pelizzo, S. Fineschi, A. J. Corso, P. Zuppella, P. Nicolosi, J. Seely, B. Kjornattanawanich, and D. L. Windt, Opt. Eng. 51, 023801-1 (2012).

109. S. Huang, B. Ji, J. Zhou, H. Li, and J. Zhu, Nucl. Instr. Meth. Phys. Res. A 832, 184 (2016).

110. A. Aquila, F. Salmassi, Y. Liu, and E. M. Gullikson, Opt. Express 17, 22102 (2009).
111. M. Vidal-Dasilva, A. L. Aquila, E. M. Gullikson, F. Salmassi, and J. I. Larruquert, J. Appl. Phys. 108, 063517 (2010).

112. C. Montcalm, P. A. Kearney, J. M. Slaughter, B. T. Sullivan, M. Chaker, H. Pe ìpin, and C. M. Falco, Appl. Opt. 35, 5134 (1996).

113. D. Xu, Q. Huang, Y. Wang, P. Li, M. Wen, P. Jonnard, A. Giglia, I. V. Kozhevnikov, K. Wang, Z. Zhang, and Z. Wang, Opt. Express 23, 33018 (2015).

114. B. Kjornrattanawanich and S. Bajt, Appl. Opt. 43, 5955 (2004).

115. B. Sae-Lao, S. Bajt, C. Montcalm, and J. F. Seely, App. Op. 41, 2394 (2002).

116. N. I. Chkhalo, S. Kuenstner, V. N. Polkovnikov, N. N. Salashchenko, F. Schaefers, and S. D. Starikov, Appl. Phys. Lett. 102, 011602 (2013)

117. I. A. Makhotkin, E. Zoethout, R. W. E. van de Kruijs, S. N Yakunin, E. Louis, A. M. Yakunin, V. Banine, S. Muellender, and F. Bijkerk, Opt. Express 21, 29894 (2013).

118. D. S. Kuznetsov, A. E. Yakshin, J. M. Sturm, R. W. E. van de Kruijs, E. Louis, and F. Bijkerk, Opt. Lett. 40, 3778 (2015).

119. R. Supruangnet, C. Morawe, J. C. Peffen, H. Nakajima, S. Rattanasuporn, P. Photongkam, N. Jearanaikoon, and W. Busayaporn, Appl. Surf. Sci. 367, 347 (2016).

120. C. Morawe, R. Supruangnet, and J. C. Peffen, Thin Solid Films 588, 1 (2015).

121. Y. Wang, Q. Huang, Q. Yi, I. V. Kozhevnikov, R. Qi, M. Wen, P. Jonnard, J. Zhang, A. Giglia, Z. Zhang, and Z. Wang, Opt. Express 25, 7749 (2017).

122. D. Xu, Q. Huang, Y. Wang, P. Li, M. Wen, P. Jonnard, A. Giglia, I. V. Kozhevnikov, K. Wang, Z. Zhang, and Z. Wang, Opt. Express 23, 33018 (2015).

123. D. L. Windt and E. M. Gullikson, Appl. Opt. 54, 5850 (2015).

124. J. F. Seely, Y. A. Uspenskii, B. Kjornrattanawanich, and D. L. Windt, Coated photodiode technique for the determination of the optical constants of reactive elements: La and Tb, Proc. SPIE 6317, Advances in X-Ray/EUV Optics, Components, and Applications, San Diego, CA, USA (2006), p. 63170T.

125. J. P. Delaboudiniere, C. Carabetian, and J. F. Hochedez, In orbit degradation of UV optical components for the wavelength range 10-140 microns, NASA, Langley Research Center, Second LDEF Post-Retrieval Symposium Abstracts (1992), p. 105

126. I. Di Sarcina, M. L. Grilli, F. Menchini, A. Piegari, S. Scaglione, A. Sytchkova, and D. Zola, Appl. Opt. 53, A314 (2014).

127. G. Naletto, A. Boscolo, J. Wyss, and A. Quaranta, Appl. Opt. 42, 3970 (2003).

128. S. Zuccon, E. Napolitani, E. Tessarolo, P. Zuppella, A. J. Corso, F. Gerlin, M. Nardello, and M. G. Pelizzo, Opt. Mater. Express 5, 176 (2015).

129. ESA, Solar orbiter environmental specification. Issue 2.0 (2008).

130. A. D. Rousseau, D. L. Windt, B. Winter, L. Harra, H. Lamoureux, and F. Eriksson, Stability of EUV multilayers to long-term heating, and to energetic protons and neutrons, for extreme solar missions, Proc. SPIE 5900, Optics for EUV, X-Ray, and Gamma-Ray Astronomy II, San Diego, CA, USA (2005), p. 590004.

131. S. Fineschi, E. Antonucci, G. Naletto, M. Romoli, D. Spadaro, G. Nicolini, L. Abbo, V. Andretta, A. Bemporad, A. Berlicki, G. Capobianco, G. Crescenzio, V. Da Deppo, M. Focardi, F. Landini, G. Massone, M. A. Malvezzi, J. Dan Moses, P. Nicolosi, M. Pancrazzi, M.-G. Pelizzo, L. Poletto, U. H. Schühle, S. K Solanki, D. Telloni, L. Teriaca, and M. Uslenghi, METIS: A novel coronagraph design for the solar orbiter mission, Proc. SPIE 8443, Space Telescopes and Instrumentation 2012: Ultraviolet to Gamma Ray, Amsterdam, NL (2012), p. $84433 \mathrm{H}$.

132. A. S. Kuznetsov, M. A. Gleeson, and F. Bijkerk, J. Appl. Phys. 114, 113507 (2013)

133. A. S. Kuznetsova, M. A. Gleeson, and F. Bijkerk, Thin Solid Film 545,571 (2013).

Received: 14 August 2017. Revised/Accepted: 8 January 2018. 